\title{
Application of nanoparticles in cast steel: An overview
}

\author{
Feng Qiu ${ }^{1}$, Tian-shu Liu ${ }^{1}$, Xin Zhang ${ }^{1}$, Fang Chang ${ }^{1}$, ** Shi-li Shu ${ }^{2,3}$, Hong-yu Yang ${ }^{1}$, Qing-long Zhao ${ }^{1}$, \\ *Qi-chuan Jiang' \\ 1. Key Laboratory of Automobile Materials, Ministry of Education and Department of Materials Science and Engineering, Jilin University, \\ Changchun 130025, China; \\ 2. State Key Laboratory of Luminescence and Applications, Changchun Institute of Optics, Fine Mechanics and Physics, Chinese Academy of \\ Sciences, Changchun 130033, China; \\ 3. School of Mechanical and Aerospace Engineering, Jilin University, Changchun 130025, China
}

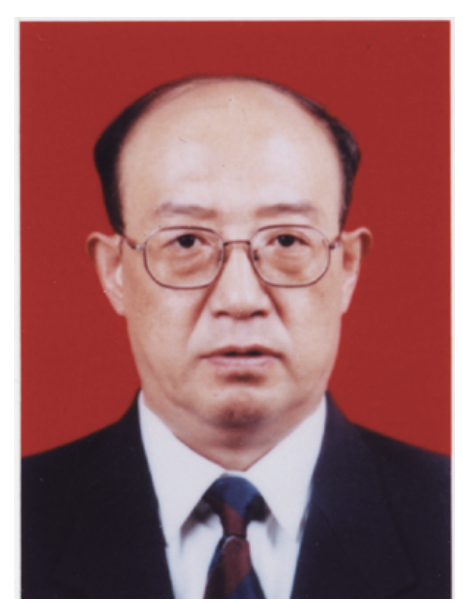

*Qi-chuan Jiang

A professor of the School of Materials Science and Engineering at Jilin University, China. Prof. Jiang is the leader of the research group of Metal Materials and Forming Processes of the Key Laboratory of Automobile Materials, Ministry of Education. He has been awarded the National Excellent Science and Technology Worker, the National Excellent Doctoral Dissertation Advisor, the China Foundry Outstanding Contribution Award (by Chinese Mechanical Engineering Society), and the Outstanding Figure of the Chinese Automobile Industry. He has been engaged in the research work on the metal solidification, and $\mathrm{Al}, \mathrm{Mg}$ and steel matrix composites for over 30 years. He has published over 390 papers in the field of metal strengthening mechanisms.

E-mail: jqc@jlu.edu.cn

**Shi-li Shu, shushili@ciomp.ac.cn

Received: 2020-03-09

Accepted: 2020-03-20
Abstract: The innovative and environmentally friendly methodologies for comprehensively enhancing the performances of high-strength steels without damage to plasticity, toughness and heat/corrosion/fatigue resistance are being developed. In recent years, nanoparticles elevate the field of high-strength steel. It is proposed that nanoparticles have the potential to replace conventional semi-coherent intermetallic compounds, carbides and alloying to optimize the steel. The fabrication process is simplified and the cost is lower compared with the traditional methods. Considerable research effort has been directed towards high-performance cast steels reinforced with nanoparticles due to potential application in major engineering. Nanoparticles are found to be capable of notably optimizing the nucleation behavior and precipitate process. The prominently optimized microstructure configuration and performances of cast steel can be acquired synchronously. In this review, the lattice matching and valence electron criterion between diverse nanoparticles and steel are summarized, and the existing various preparation methods are compared and analyzed. At present, there are four main methods to introduce nanoparticles into steel: external nanoparticle method, internal nanoparticle method, in-situ reaction method, and additive manufacturing method. These four methods have their own advantages and limitations, respectively. In this review, the synthesis, selection principle and strengthening mechanism of nanoparticles in cast steels for the above four methods are discussed in detail. Moreover, the main preparation methods and microstructure manipulation mechanism of the steel reinforced with different nanoparticles have been systematically expatiated. Finally, the development and future potential research directions of the application of nanoparticles in cast steel are prospected.

Key words: nanoparticles; high-performance steel; strengthening mechanism; preparation method; microstructure manipulation mechanism

CLC numbers: TG142; Document code: A; Article ID: 1672-6421 2020) 02-111-16

$\mathrm{T}$ o date, iron and steel materials are still the most widely used metal materials and structural materials ${ }^{[1-5]}$. The advantages of iron and steel materials are very obvious, such as rich in resources, simple in production, low in cost, various and stable in performance, and widely used. They play an important role in machinery and engineering manufacturing ${ }^{[6]}$. In recent years, mechanical engineering structures are increasingly developing towards megatrends, such as large-span bridges, long-distance oil and gas pipelines, super large ships and offshore drilling platforms ${ }^{[7,8]}$. At the same time, lightweight materials for the transportation and manufacturing industries, and the demands of tools and moulds for high performance and long service life all put forward the requirements of "high performance, high precision, easy processing, low cost 
and environmentally friendly" for iron and steel materials, that is, to obtain high uniformity, fine microstructure and consequently, high performances without increasing process difficulty and production cost ${ }^{[9]}$. High performance steel represented by ultra-high strength steel is an urgent material for national economy, national security and other key areas.

The main strengthening mechanisms of steel and other metal materials are solution strengthening, dislocation strengthening, grain refinement strengthening, second-phase dispersion strengthening and phase transformation strengthening ${ }^{[10-12]}$. Grain refinement strengthening is the only way to improve the strength and toughness of metals at the same time. Although secondphase strengthening can improve the strength of the material, it also can reduce the plasticity and toughness of the material. The reason is that although the second phase can strengthen the multiplication and interaction of dislocations, it also can reduce the density of movable dislocations. However, the fine second phase particle often has the effect of refining grains and pinning grain boundaries to prevent microstructure coarsening, which can offset the decrease of toughness ${ }^{[13,14]}$. Thus, except the grain refinement strengthening, the second-phase dispersion strengthening is the most preferred strengthening method. Therefore, the grain refinement strengthening and second-phase dispersion strengthening are the main methods of strengthening and toughening metal materials ${ }^{[15]}$.

In order to realize grain refinement strengthening and second-phase dispersion strengthening, special technology is needed. The second phase can be introduced or precipitated in the steel matrix through alloying, heat treatment, addition of nucleating agent, and reinforcement. It is found that nanosized reinforcement has a better strengthening effect than micro-sized reinforcement. However, how to introduce nanosized reinforcement into the steel matrix to realize dispersion distribution is a difficult problem because nanoparticles are very difficult to disperse due to their high surface energy. There is a specific gravity difference between the reinforcement and the molten steel. How to fundamentally solve the "bottleneck" problem that nanoparticles are difficult to introduce into the molten steel and uniformly disperse, but easy to be agglomerated and floated up, and how to realize the uniform dispersion and efficient strengthening of nanoparticles in the steel matrix, is a major problem. At present, there are four main methods to introduce nanoparticles into steel: external nanoparticle method, internal nanoparticle method, in-situ reaction method, and additive manufacturing method. These four methods have their own advantages and limitations, respectively. In this paper, the above four methods will be reviewed in detail, in order to give researchers inspiration.

In this review, the synthesis, type, selection principle, and strengthening mechanism of nanoparticles in steel and their further applications are summarized. The methods of introducing nanoparticles into the steel matrix and the mechanism of microstructure manipulation are systematically expounded. Finally, the development and some potential research directions in the future are prospected.

\section{Lattice matching and valence electron criterion between nanoparticles and steel}

Whether as nucleation phase or strengthening phase, the relationship between nanoparticles and crystal phase in steel, such as lattice mismatch, valence electron, etc., has important criteria for analyzing the nucleation efficiency and strengthening effect.

The primary phase of molten steel during solidification can be high temperature ferrite phase or austenite phase due to the different carbon content. Therefore, in the calculation of this study, the nucleation phases are $\delta$-Fe (BCC) and $\gamma$-Fe (FCC). In this section, two-dimensional mismatches of various compounds with $\gamma-\mathrm{Fe}$ and $\delta$-Fe at solidification temperature were calculated. The relationship between lattice mismatches and the effectiveness of heterogeneous nucleation catalyst was analyzed and discussed. The research work of Pan et al. ${ }^{[16]}$ showed that the smaller the mismatch between the nucleation substrate and nucleation phase, the more conducive to heterogeneous nucleation. The logarithm of supercooling is approximately linear with the two-dimensional mismatch of the nucleation substrate and nucleation phase. If the mismatch $\delta$ between nucleation substrate and nucleation phase is less than $12 \%$, the heterogeneous nucleation effect is significant. The calculation method of two-dimensional lattice mismatch is as follows ${ }^{[16,17]}$ :

$$
\delta_{(h k l)_{\mathrm{n}}}^{(h k)_{\mathrm{s}}}=\sum_{i=1}^{3} \frac{\frac{\left|d_{[u v w]_{\mathrm{s}}^{i}} \cos \theta-d_{[u v w]_{\mathrm{n}}^{i}}\right|}{d_{[u v w]_{\mathrm{n}}^{i}}}}{3} \times 100 \%
$$

where $(h k l)_{\mathrm{s}}$ is the low-index plane of nucleation substrate, $[u v w]_{\mathrm{s}}$ is the low-index direction in $(h k l)_{\mathrm{s}},(h k l)_{\mathrm{n}}$ is the low-index plane of nucleated phase, $[u v w]_{\mathrm{n}}$ is the low-index direction in $(h k l)_{\mathrm{n}}, d_{[u v w] \mathrm{s}}$ is the interatomic distance along $[u v w]_{\mathrm{s}}, d_{[u v w] \mathrm{n}}$ is the interatomic distance along $[u v w]_{\mathrm{n}}, \theta$ is the angle between $[u v w]_{\mathrm{s}}$ and $[u v w]_{\mathrm{n}}$. The mismatches of 23 common compounds (carbide, nitride, oxide and sulfide) with different low-index crystal planes of $\delta$-Fe and $\gamma$-Fe in the process of metallurgy and steel preparation at $1,500{ }^{\circ} \mathrm{C}$ were calculated. The minimum mismatch between the nucleation substrate and the different crystal planes of $\delta$-Fe and $\gamma$-Fe is taken as their mismatch, as shown in Table 1.

Figure 1 shows the relationship between supercooling degree and mismatch at $1,500{ }^{\circ} \mathrm{C}$. It can be seen from Fig. 1 that the logarithm of supercooling is approximately linear with the mismatch. Supercooling data measured by different researchers can be divided into two groups. The data are collected in Table 2. The logarithm of supercooling and the corresponding mismatch data are regressed to two straight lines, that is, the solid line in Fig. 1. The slopes of the two straight lines are similar, but the intercept is different, which may be due to different experimental methods by different authors. Bramfitt ${ }^{[17]}$ and Ohashi et al. ${ }^{[21]}$, the researchers of the 
Table 1: Crystallographic parameters of cubic, hexagonal and tetragonal compounds and their mismatch with $\delta-\mathrm{Fe}$ and $\mathrm{y}-\mathrm{Fe}{ }^{[16,18-20]}$

\begin{tabular}{|c|c|c|c|c|c|c|}
\hline \multirow{2}{*}{ Compound } & \multirow{2}{*}{ Lattice type } & \multicolumn{3}{|c|}{ Lattice constant (nm) } & \multicolumn{2}{|c|}{ Mismatch (\%) } \\
\hline & & \multicolumn{2}{|c|}{$25^{\circ} \mathrm{C}$} & $1,500^{\circ} \mathrm{C}$ & $\delta$-Fe & $\mathrm{Y}-\mathrm{Fe}$ \\
\hline$\delta-\mathrm{Fe}$ & & \multicolumn{2}{|c|}{-} & $a=0.29396$ & - & - \\
\hline $\mathrm{Y}-\mathrm{Fe}$ & & \multicolumn{2}{|c|}{-} & $a=0.36810$ & - & - \\
\hline $\mathrm{CaO}$ & $\mathrm{Fm} 3 \mathrm{~m}$ & \multicolumn{2}{|c|}{$a=0.48105$} & $a=0.49086$ & 16.51 & 5.71 \\
\hline Cas & $\mathrm{Fm} 3 \mathrm{~m}$ & \multicolumn{2}{|c|}{$a=0.56903$} & $a=0.58158$ & 1.08 & 11.72 \\
\hline $\mathrm{MgO}$ & $\mathrm{Fm} 3 \mathrm{~m}$ & \multicolumn{2}{|c|}{$a=0.42112$} & $a=0.43060$ & 3.58 & 16.98 \\
\hline MgS & $\mathrm{Fm} 3 \mathrm{~m}$ & \multicolumn{2}{|c|}{$a=0.52033$} & $a=0.53180$ & 9.54 & 2.16 \\
\hline $\mathrm{MnO}$ & $\mathrm{Fm} 3 \mathrm{~m}$ & \multicolumn{2}{|c|}{$a=0.44457$} & $a=0.45517$ & 9.49 & 12.56 \\
\hline $\mathrm{MnS}$ & $\mathrm{Fm} 3 \mathrm{~m}$ & \multicolumn{2}{|c|}{$a=0.52233$} & $a=0.53651$ & 8.74 & 3.06 \\
\hline $\mathrm{NbC}$ & $\mathrm{Fm} 3 \mathrm{~m}$ & \multicolumn{2}{|c|}{$a=0.44702$} & $a=0.45185$ & 8.69 & 13.20 \\
\hline $\mathrm{NbN}$ & $\mathrm{Fm} 3 \mathrm{~m}$ & \multicolumn{2}{|c|}{$a=0.43934$} & $a=0.44474$ & 6.98 & 14.57 \\
\hline $\mathrm{TiC}$ & $\mathrm{Fm} 3 \mathrm{~m}$ & \multicolumn{2}{|c|}{$a=0.43257$} & $a=0.43783$ & 5.32 & 15.89 \\
\hline $\mathrm{TiN}$ & $\mathrm{Fm} 3 \mathrm{~m}$ & \multicolumn{2}{|c|}{$a=0.42419$} & $a=0.43055$ & 3.57 & 16.96 \\
\hline $\mathrm{TiO}$ & $\mathrm{Fm} 3 \mathrm{~m}$ & \multicolumn{2}{|c|}{$a=0.41796$} & $a=0.42624$ & 27.69 & 15.79 \\
\hline VC & $\mathrm{Fm} 3 \mathrm{~m}$ & \multicolumn{2}{|c|}{$a=0.41819$} & $a=0.42271$ & 1.68 & 14.83 \\
\hline VN & $\mathrm{Fm} 3 \mathrm{~m}$ & \multicolumn{2}{|c|}{$a=0.41398$} & $a=0.41907$ & 0.81 & 13.85 \\
\hline $\mathrm{ZrC}$ & $\mathrm{Fm} 3 \mathrm{~m}$ & \multicolumn{2}{|c|}{$a=0.46961$} & $a=0.47496$ & 14.25 & 8.76 \\
\hline $\mathrm{ZrN}$ & $\mathrm{Fm} 3 \mathrm{~m}$ & \multicolumn{2}{|c|}{$a=0.45755$} & $a=0.46318$ & 11.42 & 11.02 \\
\hline $\mathrm{CeO}_{2}$ & $\mathrm{Fm} 3 \mathrm{~m}$ & \multicolumn{2}{|c|}{$a=0.54112$} & $a=0.55183$ & 6.14 & 6.00 \\
\hline $\mathrm{SiO}_{2}$ & $\mathrm{Fd} 3 \mathrm{~m}$ & \multicolumn{2}{|c|}{$a=0.71300$} & $a=0.71487$ & 14.02 & 2.90 \\
\hline $\mathrm{Ce}_{2} \mathrm{O}_{3}$ & P-3m1 & $a=0.38910$ & $c=0.60590$ & $a=0.39704$ & 4.49 & 14.21 \\
\hline $\mathrm{La}_{2} \mathrm{O}_{3}$ & P-3m1 & $a=0.39381$ & $c=0.61361$ & $a=0.40184$ & 3.34 & 13.17 \\
\hline $\mathrm{Al}_{2} \mathrm{O}_{3}$ & P63mc & $a=0.47589$ & $c=1.29910$ & $a=0.48224$ & 8.04 & 7.36 \\
\hline $\mathrm{Ti}_{2} \mathrm{O}_{3}$ & P63mc & - & - & $a=0.51251$ & 6.61 & 1.55 \\
\hline $\mathrm{TiO}_{2}$ & $\mathrm{P} 42 / \mathrm{mnm}$ & $a=0.45937$ & $c=0.295087$ & $c=0.30080$ & 7.69 & 8.38 \\
\hline $\mathrm{ZrO}_{2}$ & $\mathrm{P} 42 / \mathrm{nmc}$ & - & - & $c=0.52969$ & 12.14 & 0.77 \\
\hline
\end{tabular}
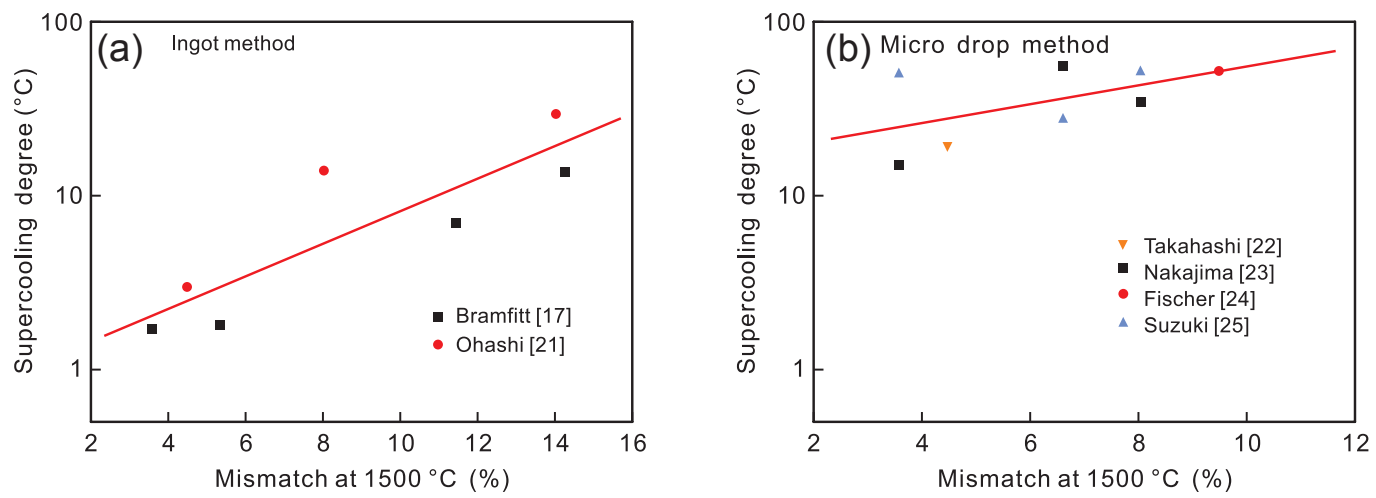

Fig. 1: Linear relationship between supercooling logarithm and mismatch ${ }^{[16-25]}$ 
Table 2: Solidification supercooling of various substrates added to $\delta-\mathrm{Fe}^{[16-25]}$

\begin{tabular}{|c|c|c|c|c|}
\hline $\begin{array}{l}\text { Measuring } \\
\text { method }\end{array}$ & $\begin{array}{l}\text { Nucleation } \\
\text { substrate }\end{array}$ & $\begin{array}{c}\text { Mismatch } \\
\text { at } 1,500{ }^{\circ} \mathrm{C}(\%)\end{array}$ & $\begin{array}{l}\text { Supercooling } \\
\text { degree }\left({ }^{\circ} \mathrm{C}\right)\end{array}$ & Author \\
\hline \multirow{7}{*}{$\begin{array}{l}\text { Ingot } \\
\text { method }\end{array}$} & TiN & 3.57 & 1.7 & Bramfitt $^{[17]}$ \\
\hline & TiC & 5.32 & 1.8 & Bramfitt $^{[17]}$ \\
\hline & $\mathrm{ZrN}$ & 11.42 & 7.0 & Bramfitt $^{[17]}$ \\
\hline & $\mathrm{ZrC}$ & 14.25 & 13.6 & Bramfitt ${ }^{[17]}$ \\
\hline & $\mathrm{Ce}_{2} \mathrm{O}_{3}$ & 4.49 & 3.0 & Ohashi ${ }^{[21]}$ \\
\hline & $\mathrm{Al}_{2} \mathrm{O}_{3}$ & 8.04 & 13.9 & Ohashi ${ }^{[21]}$ \\
\hline & $\mathrm{SiO}_{2}$ & 14.02 & 29.5 & Ohashi ${ }^{[21]}$ \\
\hline \multirow{8}{*}{$\begin{array}{l}\text { Micro drop } \\
\text { method }\end{array}$} & $\mathrm{MnO}$ & 9.49 & 52.7 & Fischer ${ }^{[24]}$ \\
\hline & $\mathrm{Ce}_{2} \mathrm{O}_{3}$ & 4.49 & 19.4 & Takahashi ${ }^{[22]}$ \\
\hline & TiN & 3.57 & 15.2 & Nakajima ${ }^{[23]}$ \\
\hline & $\mathrm{Al}_{2} \mathrm{O}_{3}$ & 8.04 & 35.0 & Nakajima ${ }^{[23]}$ \\
\hline & $\mathrm{Ti}_{2} \mathrm{O}_{3}$ & 6.61 & 56.6 & Nakajima ${ }^{[23]}$ \\
\hline & $\mathrm{Ti}_{2} \mathrm{O}_{3}$ & 6.61 & 28.7 & Suzuki ${ }^{[25]}$ \\
\hline & $\mathrm{Al}_{2} \mathrm{O}_{3}$ & 8.04 & 51.6 & Suzuki ${ }^{[25]}$ \\
\hline & $\mathrm{MgO}$ & 3.58 & 51.8 & Suzuki ${ }^{[25]}$ \\
\hline
\end{tabular}

first group of data, added substrate particles into $80 \mathrm{~g}$ and $300 \mathrm{~g}$ liquid pure iron, respectively, by ingot method, then cooled and solidified, and measured the supercooling degree. In the second group of data, researchers Takahashi ${ }^{[22]}$ and Nakajima et al. ${ }^{[23]}$ melt $0.22-0.32 \mathrm{~g}$ and $0.2 \mathrm{~g}$ pure iron, respectively, on the substrate surface into droplets, by using the micro drop method; then cooled and solidified, and measured the supercooling degree. By comparing the two sets of data, it can be seen that the supercooling measured by the ingot method is significantly lower than that measured by the micro drop method. It can be seen from Fig. 1 that as the mismatch between the nucleation substrate and $\delta$-Fe decreases, the solidification supercooling decreases. In other words, the smaller the mismatch $\delta$, the more conducive of the iron to heterogeneous nucleation. According to the lattice mismatch theory, the smaller the mismatch $\delta$, the greater the lattice matching degree between the nucleation substrate and nucleation phase, the lower the interface energy between the nucleation substrate and the nucleation phase, and the greater the possibility of heterogeneous nucleation. The theoretical description of lattice mismatch for the heterogeneous nucleation effect of nucleation substrate on the nucleation phase is consistent with the reality. The supercooling degree of $\delta$-Fe homogeneous nucleation is about $150{ }^{\circ} \mathrm{C}^{[21-22]}$. After adding the substrate (such as tin, $\mathrm{Ce}_{2} \mathrm{O}_{3}$, etc.), which has an obvious effect on the heterogeneous nucleation of $\delta$-Fe, the solidification supercooling of $\delta$-Fe decreases to about $50{ }^{\circ} \mathrm{C}[17,21-$ ${ }^{22}$. If the supercooling is less than $50^{\circ} \mathrm{C}$ as the judging condition for the obvious heterogeneous nucleation of $\delta$-Fe, according to the two straight lines regressed in Fig. 1, it can be seen that the mismatch $\delta$ should be less than $\sim 8 \%$ and $\sim 18 \%$, respectively. In this study, the criterion of heterogeneous nucleation mismatch was determined according to the solid line. In other words, in the micro drop method, when the mismatch $\delta$ is less than $8 \%$, the nucleation substrate has an obvious heterogeneous nucleation effect on the nucleation phase. According to the criterion of mismatch $\delta<8 \%$, the nucleation substrates which have significant effect on the heterogeneous nucleation of $\delta$-Fe phase are $\mathrm{VN}, \mathrm{CaS}, \mathrm{VC}, \mathrm{TiO}, \mathrm{La}_{2} \mathrm{O}_{3}, \mathrm{TiN}, \mathrm{MgO}, \mathrm{Ce}_{2} \mathrm{O}_{3}, \mathrm{TiC}$, $\mathrm{CeO}_{2}, \mathrm{Ti}_{2} \mathrm{O}_{3}, \mathrm{NbN}$. While, $\mathrm{TiO}_{2}, \mathrm{ZrO}_{2}, \mathrm{Ti}_{2} \mathrm{O}_{3}, \mathrm{MgS}$, $\mathrm{SiO}_{2}, \mathrm{MnS}, \mathrm{CaO}, \mathrm{CeO}_{2}$ and $\mathrm{Al}_{2} \mathrm{O}_{3}$ are the effective nucleation substrates for the heterogeneous nucleation of $\gamma$-Fe phase.

It is impossible to explain the phenomenon that $\mathrm{TiC}$ and $\mathrm{CaS}$ are the effective heterogeneous sites of austenite dendrites in the process of non-equilibrium solidification of austenitic steel by using the theory of interface coherent correspondence. Liang et al. ${ }^{[26]}$ reported that the interface coherent correspondence was not the essential requirement for the effective catalyst substrate by using Yu's solid and molecule empirical electron theory and the TFD (Thomas Fermi Dirac) model improved by Cheng. Based on Tillen's electrostatic effect theory, the valence electron model of the heterogeneous nucleation of austenitic steel were established. The model consists of three layers: V-Fe hybrid state stable layer, V-Fe core double lattice electron layer and core hybrid state stable layer. The valence electron criterion for evaluating the catalyst effectiveness of heterogeneous site was given. Based on this, the catalyst effectiveness of $\mathrm{VC}, \mathrm{NbC}, \mathrm{TiC}$, $\mathrm{TaC}, \mathrm{ZrC}$, and $\mathrm{CaS}$ was investigated. The advantages of catalyst effectiveness are: $\mathrm{TiC}>\mathrm{ZrC}>\mathrm{CaS}>$ $\mathrm{TaC}>\mathrm{NbC}>\mathrm{VC}^{[26]}$. Compared with the results of interface coherent theory, the catalyst effectiveness obtained by the valence electron criterion is more practical. At the same time, the wettability of $\mathrm{VC}$, $\mathrm{NbC}, \mathrm{TaC}, \mathrm{ZrC}$ and $\mathrm{TiC}$ substrates to $\mathrm{Ni}$ liquid and the catalyst effectiveness of $\mathrm{ZrC}, \mathrm{TiC}, \mathrm{TiN}$ and $\mathrm{TiO}$ substrates on heterogeneous nucleation of Au droplet were evaluated. The calculated results are in good agreement with the experimental results.

Tiller $\mathrm{W}$ et al. ${ }^{[27]}$ pointed out that the uneven distribution of free electrons between the nucleation substrate and the nucleation phase results in the migration of free electrons at the interface between the nucleation substrate and the nucleation phase, and the redistribution of free electrons results in the change of energy $\gamma_{\mathrm{e}}$. The greater the free electron mobility, the larger the absolute value of $\gamma_{\mathrm{e}}$. Because $\gamma_{\mathrm{e}}$ is always negative, the smaller the interface energy between the nucleation substrate and the nucleation phase, the more likely the heterogeneous nucleation will occur.

In classical electron theory, the method of Bond Length Difference (BLD) is used to calculate 
the valence electron structure of the constituent atoms in molecules or solids. Therefore, the empirical formula of covalent bond distance can be expressed as follows ${ }^{[18]}$ :

$$
D_{u v}\left(n_{\alpha}\right)=R_{u}(1)+R_{v}(1)-\beta \lg n_{\alpha}
$$

where $u$ and $v$ are the two bonding atoms, $n_{\alpha}$ is the value of covalent bond electron pair on the covalent bond $\alpha . D_{\mathrm{uv}}\left(n_{\alpha}\right)$ is the bond length of the covalent bond $\alpha . R_{\mathrm{u}}(1)$ and $R_{\mathrm{v}}(1)$ are the half of the bond length of the single bond, respectively. $\beta$ is the parameter determined by the electron pair of the strongest covalent bond. If the valence electron structure of the constituent atoms in the selected molecules or solids is correct, the distance of each covalent bond determined by the atomic state parameters $n_{\mathrm{c}}$ (the number of covalent bond electron), $n_{1}$ (the number of lattice electron), and $R(1)$ (the half of the bond length of the single covalent bond) should be consistent with the corresponding covalent bond distance measured in the experiment. From this, the valence electron structure of the constituent atoms in molecules or solids can be determined.

The mobility of lattice electrons can be characterized by the difference in the volume density of lattice electrons between the nucleation substrate and the nucleation phases. Therefore, the lattice electron density $\rho$ can be proposed here. For a structural unit of the crystal:

$$
\rho=\frac{1}{V} \sum_{i} n l i
$$

where $i$ represents each atom in the structural unit, while $\sum_{i} n_{l i}$ is the total number of lattice electrons of all atoms in the structural unit, and $V$ is the volume of the structural unit.

In order to characterize the mobility of lattice electrons between the nucleation substrate and the nucleation phase, the characteristic parameter $\Delta \rho$ is defined as follows:

$$
\Delta \rho=\left|\frac{2\left(\rho_{\mathrm{n}}-\rho_{\mathrm{s}}\right)}{\rho_{\mathrm{n}}+\rho_{\mathrm{s}}}\right|
$$

where $\rho_{\mathrm{s}}$ and $\rho_{\mathrm{n}}$ are the lattice electron density of the nucleation substrate and the nucleation phase, respectively.

According to classical electron theory, the valence electron structure of the constituent electrons of the nucleation substrate and the nucleation phase is calculated by the method of bond distance difference ${ }^{[18]}$. The data are listed in Table 3. According to the calculated valence electron structure, the lattice electron density $\rho$ of the nucleation substrate and the nucleation phase, and the characteristic parameter $\Delta \rho$ between the nucleation substrate and the nucleation phase are obtained. The data are listed in Table 4. Based on the electrostatic interaction theory and the classical electron theory, the larger the characteristic parameter $\Delta \rho$ between the nucleation substrate and the nucleation phase, the greater the difference in the lattice electron density between the nucleation substrate and the nucleation phase. The greater the mobility of the lattice electron, the better the heterogeneous nucleation effect. The experimental results show that the heterogeneous nucleation effect of various substrates relative to the nucleation phase described by the empirical electron theory is in accordance with the reality.

In this section, the lattice matching and valence electron criteria between various nanoparticles and steel are summarized. This will provide guidance in the selection of nanosized reinforcements for steel. In the following sections, the influence of various nanoparticles on the microstructure and mechanical properties of steels prepared by four different methods are summarized.

\section{External nanoparticle method}

While the typical production methods for metal-matrix composites are difficult and expensive, the conventional casting routes suffer from inhomogeneity and agglomeration of the added nanoparticles. The addition of nanoparticles is the simplest way to prepare nanoparticle reinforced steel ${ }^{[28-34]}$. The main bottleneck problems of the external nanoparticle method are: (i) the nanoparticles are not easily introduced into the molten steel, (ii) the nanoparticles easily agglomerate and hard to disperse, and (iii) the nanoparticles easily float up due to the high specific surface area of nanoparticles and the huge specific gravity difference between the nanosized reinforcement and the molten steel. In order to solve the above problems, the master alloy containing pre-dispersed nanoparticles is used as the carrier of nanoparticles. When the master alloy is added into the alloy melt, the nanoparticles in the master alloy are gradually dispersed into the molten steel with the dissolution of the matrix alloy, which solves the appeal problem well.

Xiao et al. ${ }^{[35]}$ proposed to improve the microstructure, stability, and the density of nano-sized $\mathrm{NbC}$ by adding $\mathrm{Ti}$, and to prepare surface-modified (NbTi)C nanoparticles to improve their distribution uniformity in the steel molten. The composites were produced by the following procedure: the $(\mathrm{NbTi}) \mathrm{C}$ nanoparticles combined with Fe powders were prepared by mechanical alloying and high-energy ball milling. Then the (NbTi)C/Fe composite powder was obtained in a vacuum tubular furnace. Finally, the 1045 steel matrix composite modified with the (NbTi) $\mathrm{C}$ nanoparticles was melted in a vacuum induction melting and casting furnace to get the cast ingot, and then air cooled to room temperature. With the addition of (NbTi)C nanoparticles, the amount of ferrite increases, and the pearlite colonies are separated by bulk ferrite, leading to the pearlite refining to an irregular shape, and the cementite lamellae degenerating into rod-like and dot-like shapes. The average diameter of (NbTi)C particles is approximately $50-200 \mathrm{~nm}$ with ellipsoid shape, and the mean grain size of the sample in which $0.14 \mathrm{wt} . \%(\mathrm{NbTi}) \mathrm{C}$ nanoparticles were added is dramatically refined and sharply decreased to $34 \mu \mathrm{m}$, while the average grain size of the as-cast steel without ( $\mathrm{NbTi}) \mathrm{C}$ nanoparticles is about $184 \mu \mathrm{m}$. With the increase of the number of (NbTi)C nanoparticles from $0 \mathrm{wt} . \%$ to $0.71 \mathrm{wt} . \%$, the hardness, yield strength and tensile strength of the as-cast 1045 steel increase from $214 \mathrm{Hv}$ to $277 \mathrm{Hv}, 376 \mathrm{MPa}$ to $535 \mathrm{MPa}$, and $499 \mathrm{MPa}$ to $754 \mathrm{MPa}$, respectively.

Li et al. ${ }^{[36]}$ fabricated the GCr15 bearing steel strengthened by trace multiphase ceramic nanoparticles with the Fe-Nb-Cr-C nanocrystalline alloy as carrier of nanoparticles, and prepared by in-situ synthesis and rapid solidification. An alloy with the same density as steel is easily directly added into the liquid 
Table 3: Calculated valence electron structure of the constituent atoms in nucleation substrate and nucleation phase ${ }^{[18]}$

\begin{tabular}{|c|c|c|c|c|c|}
\hline $\begin{array}{l}\text { Nucleation substrate or } \\
\text { nucleation phase }\end{array}$ & Atom & Hybridization & $R(1)(\mathrm{nm})$ & $n_{c}$ & $n_{1}$ \\
\hline$\delta-\mathrm{Fe}$ & $\mathrm{Fe}$ & B11 & 0.11343 & 4.0021 & 1.3319 \\
\hline $\mathrm{y}-\mathrm{Fe}$ & $\mathrm{Fe}$ & B11 & 0.11343 & 4.0021 & 1.3319 \\
\hline \multirow{2}{*}{$\mathrm{Al}_{2} \mathrm{O}_{3}$} & $\mathrm{Al}$ & 4 & 0.11900 & 2.5296 & 0.4704 \\
\hline & $\mathrm{O}$ & 1 & 0.06432 & 6.0000 & 0 \\
\hline \multirow{2}{*}{$\mathrm{CaO}$} & $\mathrm{Ca}$ & 4 & 0.12446 & 1.4670 & 0.5330 \\
\hline & $\mathrm{O}$ & 2 & 0.07084 & 2.0000 & 0 \\
\hline \multirow{2}{*}{ CaS } & $\mathrm{Ca}$ & 4 & 0.12446 & 1.4670 & 0.5330 \\
\hline & S & 3 & 0.12144 & 2.0000 & 0 \\
\hline \multirow{2}{*}{$\mathrm{Ce}_{2} \mathrm{O}_{3}$} & $\mathrm{Ce}$ & 4 & 0.15720 & 2.1765 & 0.8235 \\
\hline & O & 3 & 0.07775 & 6.0000 & 0 \\
\hline \multirow{2}{*}{$\mathrm{CeO}_{2}$} & $\mathrm{Ce}$ & 4 & 0.15720 & 2.1765 & 0.8235 \\
\hline & $\mathrm{O}$ & 2 & 0.07084 & 6.0000 & 0 \\
\hline \multirow{2}{*}{$\mathrm{La}_{2} \mathrm{O}_{3}$} & La & 5 & 0.16212 & 2.2922 & 0.7078 \\
\hline & $\mathrm{O}$ & 3 & 0.07775 & 6.0000 & 0 \\
\hline \multirow{2}{*}{$\mathrm{MgO}$} & $\mathrm{Mg}$ & 3 & 0.12604 & 1.3022 & 0.6978 \\
\hline & 0 & 1 & 0.06432 & 6.0000 & 0 \\
\hline \multirow{2}{*}{ MgS } & $\mathrm{Mg}$ & 3 & 0.12604 & 1.3022 & 0.6978 \\
\hline & $S$ & 3 & 0.12144 & 6.0000 & 0 \\
\hline \multirow{2}{*}{$\mathrm{MnO}$} & $\mathrm{Mn}$ & 9 & 0.12013 & 3.6203 & 0.6898 \\
\hline & $\mathrm{O}$ & 4 & 0.07895 & 2.0000 & 0 \\
\hline \multirow{2}{*}{ MnS } & $\mathrm{Mn}$ & 9 & 0.12013 & 3.6203 & 0.6898 \\
\hline & $S$ & 3 & 0.07775 & 2.0000 & 0 \\
\hline \multirow{2}{*}{$\mathrm{NbC}$} & $\mathrm{Nb}$ & B3 & 0.13267 & 4.0377 & 0.9623 \\
\hline & C & 6 & 0.07630 & 4.0000 & 0 \\
\hline \multirow{2}{*}{$\mathrm{NbN}$} & $\mathrm{Nb}$ & B3 & 0.13267 & 4.0377 & 0.9623 \\
\hline & $\mathrm{N}$ & 1 & 0.07165 & 3.0000 & 0 \\
\hline \multirow{2}{*}{$\mathrm{SiO}_{2}$} & Si & 4 & 0.11700 & 3.6638 & 0.3362 \\
\hline & O & 1 & 0.06432 & 6.0000 & 0 \\
\hline \multirow{2}{*}{$\mathrm{TiC}$} & $\mathrm{Ti}$ & B10 & 0.12373 & 3.3858 & 0.6142 \\
\hline & C & 6 & 0.07630 & 4.0000 & 0 \\
\hline \multirow{2}{*}{$\mathrm{TiO}$} & $\mathrm{Ti}$ & B10 & 0.12373 & 3.3858 & 0.6142 \\
\hline & O & 2 & 0.07084 & 6.0000 & 0 \\
\hline \multirow{2}{*}{$\mathrm{Ti}_{2} \mathrm{O}_{3}$} & $\mathrm{Ti}$ & B10 & 0.12373 & 3.3858 & 0.6142 \\
\hline & $\mathrm{O}$ & 3 & 0.7775 & 6.0000 & 0 \\
\hline \multirow{2}{*}{$\mathrm{TiO}_{2}$} & $\mathrm{Ti}$ & B10 & 0.12373 & 3.3858 & 0.6142 \\
\hline & $\mathrm{O}$ & 3 & 0.7775 & 6.0000 & 0 \\
\hline \multirow{2}{*}{ VC } & V & $\mathrm{C} 7$ & 0.11413 & 3.2609 & 1.4783 \\
\hline & $\mathrm{C}$ & 4 & 0.07630 & 3.6638 & 0.3362 \\
\hline \multirow{2}{*}{ VN } & V & $\mathrm{C} 7$ & 0.11413 & 3.2609 & 1.4783 \\
\hline & $\mathrm{N}$ & 1 & 0.07165 & 3.0000 & 0 \\
\hline \multirow{2}{*}{$\mathrm{ZrC}$} & $\mathrm{Zr}$ & B10 & 0.14039 & 3.3858 & 0.6142 \\
\hline & C & 6 & 0.07630 & 4.0000 & 0 \\
\hline \multirow{2}{*}{$\mathrm{ZrN}$} & $\mathrm{Zr}$ & B10 & 0.14039 & 3.3858 & 0.6142 \\
\hline & $\mathrm{N}$ & 1 & 0.07165 & 5.0000 & 0 \\
\hline \multirow{2}{*}{$\mathrm{ZrO}_{2}$} & $\mathrm{Zr}$ & B10 & 0.14039 & 3.3858 & 0.6142 \\
\hline & $\mathrm{O}$ & 3 & 0.07775 & 6.0000 & 0 \\
\hline
\end{tabular}


Table 4: Calculated lattice electron density $\rho$ of the nucleation substrate and the nucleation phase, and the characteristic parameter $\Delta \rho$ between the nucleation substrate and nucleation phase ${ }^{[18]}$

\begin{tabular}{|c|c|c|c|}
\hline Nucleation substrate & $\begin{array}{l}\text { Electron density } \\
\rho\left(\mathrm{e} \cdot \mathrm{nm}^{-3}\right)\end{array}$ & $\begin{array}{c}\text { Characteristic parameter } \\
\Delta \rho(\bar{\delta}-\mathrm{Fe})\end{array}$ & $\begin{array}{c}\text { Characteristic parameter } \\
\Delta \rho(\mathrm{V}-\mathrm{Fe})\end{array}$ \\
\hline $\mathrm{Al}_{2} \mathrm{O}_{3}$ & $2.216 \times 10^{4}$ & 1.345 & 1.354 \\
\hline $\mathrm{CaO}$ & $1.915 \times 10^{4}$ & 1.421 & 1.429 \\
\hline Cas & $1.157 \times 10^{4}$ & 1.629 & 1.634 \\
\hline $\mathrm{Ce}_{2} \mathrm{O}_{3}$ & $2.073 \times 10^{4}$ & 1.380 & 1.389 \\
\hline $\mathrm{CeO}_{2}$ & $2.079 \times 10^{4}$ & 1.379 & 1.388 \\
\hline $\mathrm{La}_{2} \mathrm{O}_{3}$ & $1.718 \times 10^{4}$ & 1.473 & 1,480 \\
\hline $\mathrm{MgO}$ & $3.738 \times 10^{4}$ & 1.006 & 1.019 \\
\hline MgS & $1.981 \times 10^{4}$ & 1.404 & 1.412 \\
\hline $\mathrm{MnO}$ & $3.140 \times 10^{4}$ & 1.131 & 1.142 \\
\hline MnS & $1.936 \times 10^{4}$ & 1.415 & 1.424 \\
\hline $\mathrm{NbC}$ & $4.309 \times 10^{4}$ & 0.896 & 0.910 \\
\hline $\mathrm{NbN}$ & $4.539 \times 10^{4}$ & 0.854 & 0.868 \\
\hline $\mathrm{SiO}_{2}$ & $0.736 \times 10^{4}$ & 1.756 & 1.759 \\
\hline $\mathrm{TiC}$ & $3.035 \times 10^{4}$ & 1.154 & 1.165 \\
\hline TiN & $3.219 \times 10^{4}$ & 1.114 & 1.126 \\
\hline TiO & $3.365 \times 10^{4}$ & 1.083 & 1.095 \\
\hline $\mathrm{Ti}_{2} \mathrm{O}_{3}$ & $2.322 \times 10^{4}$ & 1.319 & 1.328 \\
\hline $\mathrm{TiO}_{2}$ & $1.968 \times 10^{4}$ & 1.407 & 1.416 \\
\hline VC & $9.924 \times 10^{4}$ & 0.131 & 0.148 \\
\hline VN & $8.334 \times 10^{4}$ & 0.303 & 0.320 \\
\hline $\mathrm{ZrC}$ & $2.372 \times 10^{4}$ & 1.307 & 1.316 \\
\hline $\mathrm{ZrN}$ & $2.565 \times 10^{4}$ & 1.261 & 1.271 \\
\hline $\mathrm{ZrO}_{2}$ & $1.738 \times 10^{4}$ & 1.467 & 1.475 \\
\hline
\end{tabular}

steel, so the main component of $\mathrm{Fe}-\mathrm{Nb}-\mathrm{Cr}-\mathrm{C}$ nanocrystalline alloy to refine GCr15 is iron. With 93.0wt.\% cast iron, 6.5wt.\% pure niobium and $0.5 \mathrm{wt} . \%$ pure chromium as raw materials, $\mathrm{Fe}-\mathrm{Nb}-\mathrm{Cr}-\mathrm{C}$ mother alloy is obtained in vacuum furnace. Then, in the rapid vacuum quenching furnace, the master alloy is made into ribbon by melt spun. The results show that a large number of ceramic particles are distributed in the $\mathrm{Fe}-\mathrm{Nb}-\mathrm{Cr}-\mathrm{C}$ master alloy. Compared with the traditional treatment process, after modification and heat treatment, the microstructure of the GCr15 has been significantly optimized as follows: the matrix grain of GCr15 is obviously refined, the number of carbide particles is increased, and the sizes of all kinds of carbide particles are reduced obviously. They found that the heterogeneous nucleation of ceramic nanoparticles in bearing steel and the $\mathrm{Cr}_{7} \mathrm{C}_{3}$ nanoparticles in the master alloy induced the formation of $\mathrm{M}_{7} \mathrm{C}_{3}$ carbides in the matrix of GCr15. Therefore, the amount of the second phase is greatly increased and the steel matrix is significantly strengthened. The hardness, wear resistance, impact toughness and yield strength of the GCr15 bearing steel have been significantly improved, respectively. In particular, after adding nanoparticles, the tensile strength of the tempered GCr15 bearing steel reaches 2,025.7 MPa, and the elongation after fracture is about 1.54 times that of the unmodified GCr15. In conclusion, the addition of nanoparticles can significantly refine the microstructure of the steel, increase the amount of the second phase and improve the strength and plasticity of the steel. It can be seen that the strengthening effect of trace nanoparticles on steel is significant.

In authors' previous work ${ }^{[37,38]}$, the trace nanoparticle reinforced cast $40 \mathrm{Cr}$ steel was also prepared by adding nanoparticles into the molten steel based on pre-dispersed nanosized bi-phase $\mathrm{TiC}-\mathrm{TiB}_{2} / \mathrm{Al}$ master alloy. The master alloy mainly contains $\alpha$-Al, spherical TiC particles and prisms or lamellar $\mathrm{TiB}_{2}$ particles. The particles are separated by aluminum without obvious agglomeration. The average particle size of the mixed particles is $190 \mathrm{~nm}$. The pre-dispersed nanosized biphase $\mathrm{TiC}-\mathrm{TiB}_{2} / \mathrm{Al}$ master alloy is put into the ladle, then the molten steel is flushed into the ladle, the master alloy is melted, and the nanoparticles are gradually dispersed in the molten steel. The aluminum in the master alloy can also be simultaneously used as an oxygen scavenger to react with oxygen to form $\mathrm{Al}_{2} \mathrm{O}_{3}$ at a high temperature. Then, the $\mathrm{Al}_{2} \mathrm{O}_{3}$ is removed during the melting process. This method not only successfully introduces nanoparticles into the molten steel, but also contributes to the 
uniform dispersion of nanoparticles and the removal of oxygen from the steel. The experimental results show that a series of significant changes have taken place in the microstructure of the steel: the ferrite-pearlite structure of the as-cast steel and the bainite structure of the steel after heat treatment are refined, the grain size is reduced, and the content of carbide nanoparticles is increased remarkably. The refinement of the microstructure is caused by the enhancement of nucleation and the inhibition of the dendrite growth by the bi-phase $\mathrm{TiC}-\mathrm{TiB}_{2}$ nanoparticles. The refined microstructure with evenly dispersed nanoparticles offers better properties: yield strength $(1,246 \mathrm{MPa})$, tensile strength $(1,469 \mathrm{MPa})$, fracture strain (9.4\%), impact toughness $\left(20.3 \mathrm{~J} \cdot \mathrm{cm}^{-2}\right)$ and hardness (41 HRC) for the steel with 0.018 wt. $\%$ bi-phase $\mathrm{TiC}_{x}-\mathrm{TiB}_{2}$ nanoparticles, which are increased by $15.4 \%, 31.2 \%, 4.4 \%, 11.5 \%$, and $7.9 \%$ compared with the $40 \mathrm{Cr}$ steels without nanoparticles.

The external addition method is to add the prepared fine particles into the molten steel from the outside in the process of melting or casting. Compared with in-situ precipitation method, the size and quantity of the nanoparticles are more controllable. There is no high requirement for the purity of molten steel, the production process is simple, and the energy consumption is low. Moreover, the nanoparticles play an important role in refining the solidification microstructure of steel materials and the subsequent hot working process ${ }^{[39,40]}$. Although there are still some problems in the external nanoparticle method, the master alloy method has achieved the introduction of nanoparticles into the steel matrix successfully, and the effect on microstructure manipulation and performance strengthening is significant. This provides a new method for us to prepare trace nanoparticle reinforced steels with a pre-dispersed nanoparticle master alloy.

\section{Internal nanoparticle method}

Internal nanoparticle method is the main method to prepare nanoparticles strengthening steels. The traditional medium- and high-carbon alloy steels can be regarded as internal nano-sized carbide strengthening steels ${ }^{[41]}$. In general, uniform dispersion and precipitation of in-situ nanoparticles can be achieved by optimization of the heat treatment process, deformation induced precipitation, and alloying ${ }^{[2,43]}$. Optimization of the heat treatment process is the main method to control the precipitation and distribution of nanoparticles. The microstructure of carbidefree bainite/martensite steel is refined, and hydrogen diffuses more slowly in the steel, thus improving the corrosion fatigue property ${ }^{[44]}$. Mazaheri et al. ${ }^{[45]}$ found that ultrafine equiaxed ferrite and homogeneously distributed martensite islands were acquired, and ultrahigh tensile strength and appropriate ductility were obtained in cold-rolled dual phase steel by intercritical annealing at $790{ }^{\circ} \mathrm{C}$ for $8 \mathrm{~min}$ and quenching with water. In terms of $9 \mathrm{Cr}-1.7 \mathrm{~W}-0.1 \mathrm{C}$ reduced activated ferriticmartensitic steel which is usually operated at high temperature, lower normalizing temperature will lead to more and finer carbides, thus ensuring high yield strength ${ }^{[46]}$. The size and dispersity of the second phase dispersion such as precipitates and intermetallics also determine the performances of steels. It is found that the dispersion of second phase particles can be improved by repeated forging at high temperature. The excellent creep resistance of $\mathrm{Fe}-\mathrm{Al}$ alloys at high temperature is induced by the uniform distribution of fine second phase particles ${ }^{[47]}$. Moreover, Ren et al. ${ }^{[48]}$ found that the second phase containing $\mathrm{Ti}, \mathrm{Al}, \mathrm{Si}, \mathrm{Mn}$ and $\mathrm{S}$ can serve as the nucleation sites of blisters which have high binding energy to hydrogen. Under the pressure of hydrogen, blisters can propagate discontinuously or continuously. $\mathrm{Xu}$ et al. ${ }^{[49]}$ studied the nanoscale precipitation and its influence on the strengthening mechanism in lowcarbon ultra-high strength steel, which was hot-rolled at different temperatures and subjected to various isothermal aging conditions. The steel has a yield strength of $\sim 1,730 \mathrm{MPa}$ and elongation-to-failure of $\sim 13 \%$ under the peak aging condition, of which $\sim 740 \mathrm{MPa}$ is contributed by precipitation strengthening.

Combined with heat treatment in the process of deformation, deformation induced precipitation can realize nano strengthening in the process of profile preparation. Tian et al. ${ }^{[50]}$ studied the effect of deformation on the precipitation hardening behavior of a $2.8 \mathrm{GPa}$ maraging steel. The experimental steel was firstly melted in a $300 \mathrm{~kg}$ vacuum induction furnace and then remelted in a vacuum arc melting furnace. After homogenization at 1,250 ${ }^{\circ} \mathrm{C}$ for $24 \mathrm{~h}$, the ingot was hot forged into $100 \mathrm{~mm}$ square rods at $1,100{ }^{\circ} \mathrm{C}$ followed by air-cooling. The bars cut from the forged rods were solution treated at $850^{\circ} \mathrm{C}$ for $1 \mathrm{~h}$ in a vacuum furnace and then quenched with water. The specimens with a thickness of $5 \mathrm{~mm}$ were cut from the quenched bar and then cold rolled to a final thickness of $3 \mathrm{~mm}$ and $0.5 \mathrm{~mm}$ to achieve a $40 \%$ and $90 \%$ thickness reduction at ambient temperature, respectively. Finally, the specimens were aged at $480{ }^{\circ} \mathrm{C}$ for different times and then air cooled to ambient temperature. The hardness of the quenched specimen is $291.4 \mathrm{HV}$, which increases to $379.7 \mathrm{HV}$ and 390.3 HV after $40 \%$ and $90 \%$ thickness reduction, respectively. The typical lath martensite microstructure with high dislocations density can be identified, while the matrix is clean without visible precipitates. The specimens treated at peak aging condition (quenched specimen) show dispersed nano-size precipitates in the matrix, which are finally identified as $\mathrm{Ni}_{3}(\mathrm{Ti}, \mathrm{Mo})$.

On the basis of heat treatment process, it is a hot topic to control the composition and size of precipitates by adding certain elements or compounds. Kim et al. ${ }^{[51]}$ reported that the FeAl-type hard intermetallic compound (B2) was introduced as the strengthening second phase into the high-aluminium lowdensity steel to alleviate the harmful effect of intermetallic compound on the ductility of Fe-based alloy by controlling its morphology and dispersion. The high-specific-strength steel (HSSS) sample was produced in an induction melting furnace under argon atmosphere with a heat treatment process in the order of homogenization, hot and cold rolling, annealing and water quenching. When the local recrystallization proceeds quickly during annealing, the B2 phase precipitates in the size of 200-1000 nm at the grain boundaries of recrystallized fine austenite to form the microstructure of fine particles distributed between B2-stringer bands in the steel matrix. Otherwise, B2 
phase precipitates in the size of 50-300 $\mathrm{nm}$ along the shear bands in the non-recrystallized coarse austenite grains. The dislocations pile up or bend at the phase interface and the B2 particles are not sheared by gliding dislocations leading to high work-hardening rate and ultrahigh yield strength. As shown in Fig. 2, after thermal treated at $900{ }^{\circ} \mathrm{C}$ for 2 min and then cooled at the rate of $30^{\circ} \mathrm{C} \cdot \mathrm{s}^{-1}$, the specific ultimate tensile strength, the specific yield strength and the tensile elongation of the HSSS are $227 \mathrm{MPa} \cdot \mathrm{g}^{-1} \cdot \mathrm{cm}^{3}, 199 \mathrm{MPa} \cdot \mathrm{g}^{-1} \cdot \mathrm{cm}^{3}$ and $20.3 \%$, respectively, which are 1.5 times, 1.7 times and 10 times that of 2000 series $\mathrm{Al}$ alloy, respectively. Also, these properties are significantly higher than those of the $k$-carbide-strengthened TRIPLEX steel and the fully martensitic press hardening steel (PHS), and almost the same strength as that of the Ti6Al4V titanium alloy with better plasticity. It shows great potential of lightweight application.
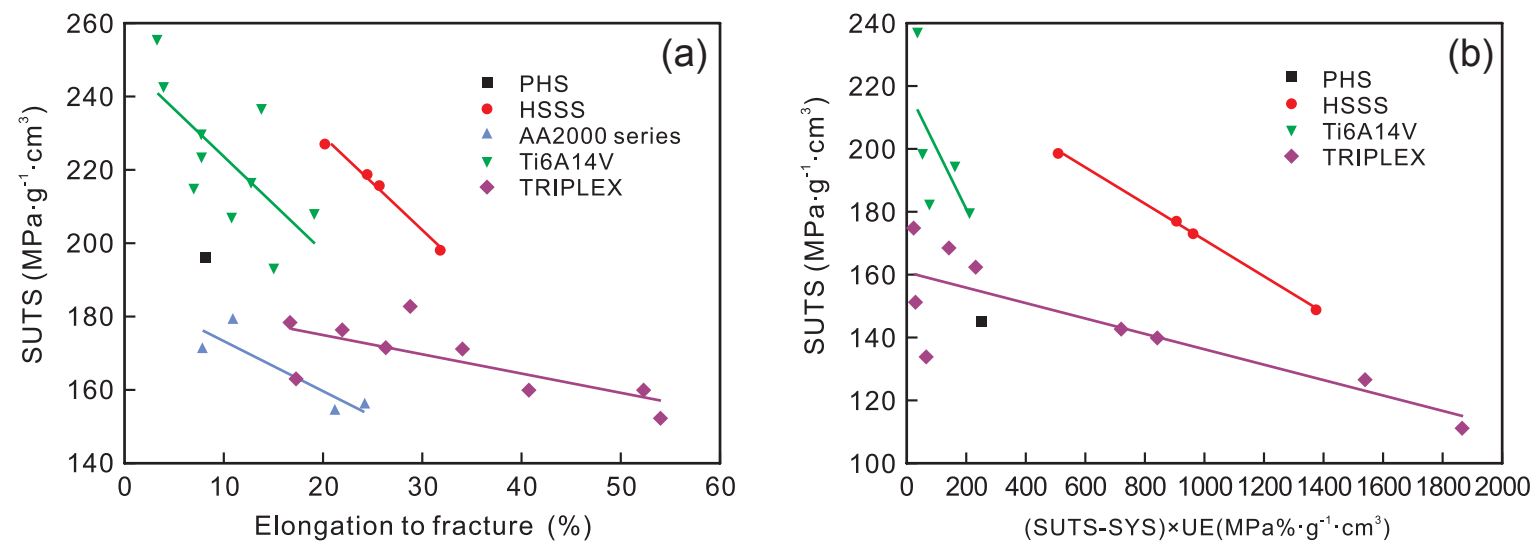

Fig. 2: (a) Specific ultimate tensile strength (SUTS) versus elongation to fracture of HSSS compared with press hardening steel (PHS) and the available literature data ${ }^{[51-59]}$ (AA2000 is a commercial aluminium alloy); (b) Specific yield strength (SYS) versus density-compensated tensile toughness increased during uniform elongation (UE) of HSSS compared with the selected metallic alloys with high specific strength ${ }^{[51-56]}$

This is also a way to achieve nano-TiC precipitation by adding Ti element. Huang et al. ${ }^{[60]}$ used in-situ nanoTiC particles to further enhance the wear resistance of low alloy wear resistant steel without increasing hardness to avoid deterioration of the forming, processing and welding performance of the steel. The microstructure of all steels after heat treatment is martensite, but with the increase of Ti content, the martensite microstructure becomes finer, and a large number of fine TiC particles (300-400 $\mathrm{nm}$ in diameter) are distributed in the martensite matrix. The higher the content of $\mathrm{Ti}$ in steel, the higher the content of $\mathrm{Ti}$ dissolves and the finer the particles generate. There are two types of nano-sized TiC precipitation: spherical and cylindrical. Although the TiC particles consumed the $\mathrm{C}$ element in the matrix, thus reducing the hardness and strength of the experimental steels, the wear resistance did not decrease. In terms of wear performance, the mass loss is inversely proportional to the $\mathrm{TiC}$ particle content. Specifically, the microhardness of the $0.6 \mathrm{Ti}$ steel and $0.015 \mathrm{Ti}$ steel is $404 \mathrm{HBW}$ and $507 \mathrm{HBW}$, respectively, while the mass loss of the $0.6 \mathrm{Ti}$ steel and $0.015 \mathrm{Ti}$ steel is $2.1 \mathrm{~g}$ and $2.6 \mathrm{~g}$, respectively. In Celada-Casero's work ${ }^{[61]}$, under different isochronal conditions, decreasing the heating rate will increase the volume fraction of nanometric $\mathrm{Ni}_{3}(\mathrm{Ti}, \mathrm{Al})$ particles and promote the partial recovery of martensite in $12 \mathrm{Cr}-9 \mathrm{Ni}-4 \mathrm{Mo}-2 \mathrm{Cu}-1 \mathrm{Ti}-0.4 \mathrm{Al}$ steel. The microstructure heated at $0.1{ }^{\circ} \mathrm{C} \cdot \mathrm{s}^{-1}$ exhibits larger precipitates than that austenitized at $10{ }^{\circ} \mathrm{C} \cdot \mathrm{s}^{-1}$. Shi et al. ${ }^{[62]}$ investigated the microstructure evolution of in situ nanoparticles and their effects on the mechanical properties of HSLA100 and the strengthening mechanism. During the experiment, as shown in Fig. 3, the steel was melted in a vacuum melting furnace, and the Al and $\mathrm{Ti}$ alloying elements were added in the form of $\mathrm{Al}$ and $\mathrm{Ti}$ compound twisted wires to the melt by the trace-element regional supply method. At the same time, argon was blown from the bottom before the last stage of casting. The inclusions in the as-cast steel have a core-shell structure, in which the core is mainly $\mathrm{Al}_{2} \mathrm{O}_{3}$ with a small quantity of $\mathrm{Ti}$ and the shell is $\mathrm{MnS}$, as well as a small amount of $\mathrm{CaS}$ with an average size of $2 \mu \mathrm{m}$. The second phase is $\mathrm{Ti}_{3} \mathrm{O}_{5}$ with a monoclinic structure, whereas the matrix is a body-centered cubic $\alpha$-Fe structure. In addition, a large number of nanoparticles are uniformly dispersed in the matrix with a diameter of 5-10 $\mathrm{nm}$. Chemical composition analysis shows that the

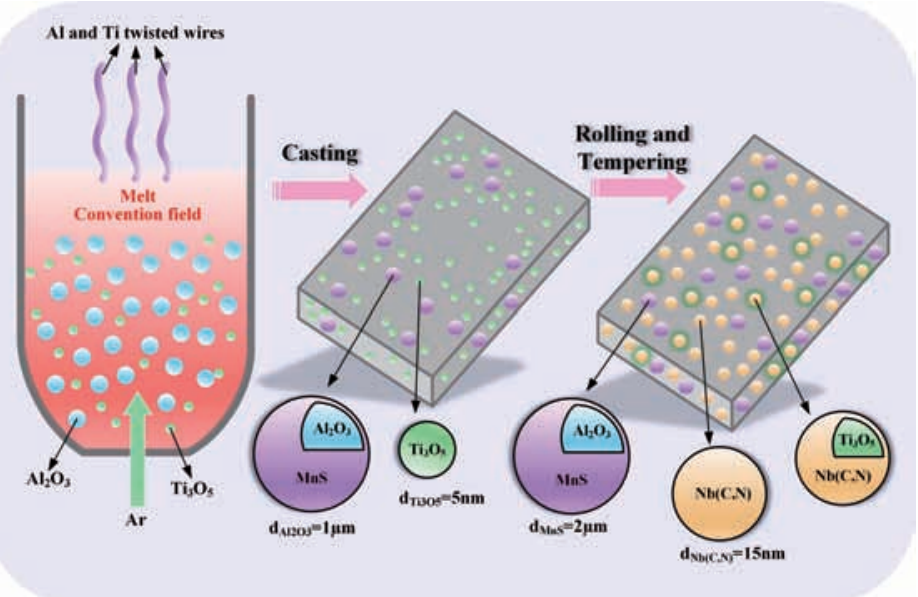

Fig. 3: Schematic of the trace element regional supply method, and the microstructure evolution in casting and tempering process ${ }^{[62]}$ 
precipitates in the tempered steel are mainly $\mathrm{Nb}(\mathrm{C}, \mathrm{N})$ and $\mathrm{Ti}_{3} \mathrm{O}_{5}$. If there are no in situ nanoparticles, the $\mathrm{Nb}(\mathrm{C}, \mathrm{N})$ can nucleate on grain boundaries or dislocations. Gao et al. ${ }^{[63]}$ investigated the deformation behaviors of Fe-0.18C-1.45Si-1.47Mn (wt.\%) $\alpha$-iron nanopillars by in-situ transmission electron microscopy. One nanopillar contains no Ti nor Mo (labeled Ti-Mo-free steel), the other contains $0.1 \mathrm{wt} . \%$ Ti and $0.19 \mathrm{wt} . \%$ Mo (labeled Ti-Mo-bearing steel). Result indicates that the Ti and Mo promote the carbide to precipitate along the interphase. The insitu observation provides a direct evidence that the movement of dislocations is limited by the interphase-precipitated nano carbides, resulting in a small improvement of strain and a significantly enhancement of strength.

Rare earth elements can not only purify the molten steel, but also can significantly enhance the properties of steel by the oxide nanoparticles formed during rare earth purification ${ }^{[64,65]}$. The creep property of $9 \mathrm{Cr}$ F/M steel was improved by the addition of yttrium. Although the initial creep rates of $9 \mathrm{Cr}-0 \mathrm{Y}$ and $9 \mathrm{Cr}-0.3 \mathrm{Y}$ are almost the same, the creep rupture life of $9 \mathrm{Cr}-0.3 \mathrm{Y}$ is about 2-3 times longer than that of $9 \mathrm{Cr}-0 \mathrm{Y}$, and the longer the steady state creep stage, the lower the minimum creep rate. During the creep process, the grains and martensitic laths are coarsened. $\mathrm{M}_{23} \mathrm{C}_{6}$ carbides, $\mathrm{MX} / \mathrm{M}_{2} \mathrm{X}$-type carbonitrides and $\mathrm{Fe}_{2} \mathrm{~W} / \mathrm{Mo}$ Laves phase appeared along the boundary in both specimens. For $9 \mathrm{Cr}-0.3 \mathrm{Y}$, due to the diffusion and local segregation of dissolved yttrium and oxygen atoms at high temperature and the promotion of creep stress, the nano-sized oxide clusters are formed during creep. The softening of microstructure recovery is compensated by the dispersion strengthening of nano-particles and the balance of them is the reason for longer steady state creep stage of the creep curves. In Qiu's work ${ }^{[66]}$, martensitic laths were found in $\mathrm{Fe} 0.11 \mathrm{C} 9.1 \mathrm{Cr} 1.71 \mathrm{~W}$ steel, and $\mathrm{Y}_{2} \mathrm{O}_{3}$ precipitated on the lath boundary. $\mathrm{Y}_{2} \mathrm{O}_{3}$ precipitates with a size of approximately $180 \mathrm{~nm}$ were observed at the sub-grain boundary. The presence of nanosized $\mathrm{Y}_{2} \mathrm{O}_{3}$ indicates that the ESR process removes the larger inclusions and retains the submicron-sized inclusions. Some Tiand $\mathrm{W}$-containing precipitates with a size of about $20 \mathrm{~nm}$ were also found in the alloy, which were identified as $(\mathrm{Ti}, \mathrm{W}) \mathrm{C}$, while in Zhan's work ${ }^{[67]}$, $\mathrm{Y}$ and $\mathrm{Y}-\mathrm{Zr}$ were respectively added to $9 \mathrm{Cr}$ RAFM steel. The experiment was carried out in a vacuum casting equipment with an electromagnetic stirrer. There are abundant fine Y-S-O particles and Y-Zr-S-O particles in the two doped steels, respectively. The density of fine particles (size $<500 \mathrm{~nm}$ ) in steels is about $1.06 \times 10^{17}$ and $9.82 \times 10^{16} \mathrm{~m}^{-3}$, respectively.

According to the above introduction, nanoparticle reinforced steel can be effectively prepared by adding alloying elements, combining with appropriate plastic forming process and heat treatment process. The method is simple and efficient, and the effect of microstructure manipulation and strengthening is remarkable. However, some alloying elements with high cost need to be added, which is very sensitive to the heat treatment process.

\section{In-situ reaction method}

The most representative method of in-situ reaction method is powder metallurgy ${ }^{[68]}$, but in the manufacturing process, there will be pollution, and it is difficult to prepare large-scale and complex-shape structural components, and the cost is very high. Considering the cost of adding alloying elements, it is a very ingenious idea to use impurity elements in the steelmaking process to realize the purification of impurity elements, transform impurity elements into treasure and form nanoparticles for strengthening steel. Nanosized oxide dispersion-strengthened steel is a special method developed from in-situ reaction method. Nanosized in-situ oxide dispersion-strengthened (ODS) steel is one of the most promising structural metal materials ${ }^{[69,70]}$. The stable nano-sized oxides with uniform dispersion can effectively hinder dislocations and pin on grain boundaries. In order to establish a fantastic microstructure and improve the performance of ODS steel, a lot of research has been carried out. Through previous studies ${ }^{[71]}$, it is found that the size and dispersion of oxide, and the orientation relationship between oxide and matrix are the main factors to optimize the microstructure and performance of ODS steels. Zr was added to ODS steels ${ }^{[72]}$, the precipitated oxide particles (rhombohedral $\mathrm{Y}_{4} \mathrm{Zr}_{3} \mathrm{O}_{12}$ ) were in fine sizes and coherent or semi-coherent with the matrix. The fine precipitated particles can prevent dislocations from moving, thus improving the strength and ductility simultaneously. The nano- $\mathrm{Y}_{2} \mathrm{Ti}_{2} \mathrm{O}_{7}$ particles are located at the grain boundaries ${ }^{[73]}$. The oxide particles containing $\mathrm{Cu}, \mathrm{Y}$ and $\mathrm{O}$ elements are located inside the grains and precipitated in nano-sized. Most of the particles gather in the Y-rich phase and wrap around the $\mathrm{Cu}$ rich phase. The Y-rich phase is semi-coherent with the matrix, and the $\mathrm{Cu}$-rich phase is beneficial to the precipitation of Y-rich phase. Thus, the high-temperature mechanical properties are improved due to the ultrafine grains and the nano-sized oxide particles. Dou et al. ${ }^{[74]}$ found that the dispersion of oxide particles was significantly promoted and the formation of Y-Al-O was inhibited due to the addition of $\mathrm{Zr}$ in $\mathrm{Fe}-15 \mathrm{Cr}-2 \mathrm{~W}-$ 0.5Ti-7Al-0.4Zr-0.5 $\mathrm{Y}_{2} \mathrm{O}_{3}$ alloy. Besides, the oxide nanoparticles composed of $\mathrm{Y}_{4} \mathrm{Zr}_{3} \mathrm{O}_{12}$ and $\mathrm{Y}_{2} \mathrm{Zr}_{2} \mathrm{O}_{7}$ have a coherent or semicoherent relationship with the steel matrix. Hence, the strength, irradiation damage resistance and corrosion resistance are significantly optimized. ODS Eurofer steel strengthened by Y-(Ce, Hf, La, Sc, and Zr) complex oxides ${ }^{[75]}$ was studied and compared as well. It was found that the precipitates pinned on the grain boundaries of ODS steel can refine the dispersoid. The results show that the particle spacing is an important factor to control the strengthening effect of dispersoid, that is, the lower particle spacing has a greater contribution to the yield strength. After Y-(Ce, Hf, La, Sc, and Zr) complex oxides strengthening, the yield strength of ODS steel is improved, and the microstructure with the finest size and the lowest particle spacing has the highest strength. Nano-sized $\mathrm{MnSiO}_{3}$ was observed in austenitic stainless steel, and the grain growth was hindered by Zener-pinning effect ${ }^{[76]}$. At $1,200{ }^{\circ} \mathrm{C}$, it was found that the metastable Rhodonite particles transformed into stable $\mathrm{MnCr}_{2} \mathrm{O}_{4}$. In this way, nano-sized $\mathrm{MnCr}_{2} \mathrm{O}_{4}$ particles were used to refine the microstructure and enhance the strength. Adding nano- $\mathrm{TiO}_{2}$ particles into the weld bead has a great contribution to the improvement of the strength, ductility and especially the 
toughness, which is mainly due to the increase of the size and surface density of acicular ferrite with the increase of Ti content in inclusions ${ }^{[77]}$. $\mathrm{Gd}_{2} \mathrm{O}_{3}$ and Ti were added into nickel alloy by mechanical alloying. Both the grains and precipitates $\left(\mathrm{Gd}_{2} \mathrm{TiO}_{5}\right)$ were refined, and the particle spacing was decreased. After the addition, the distribution of precipitates is more uniform ${ }^{[78]}$. It is also found that there is no intermetallic reaction at the interface of $\mathrm{Al}_{2} \mathrm{O}_{3} /$ steel, and the interface of nano- $\mathrm{Al}_{2} \mathrm{O}_{3}$ particles and Mn$\mathrm{Cr}$ steel is well bonded. Their dissolution leads to the formation of Ti-based nanoprecipitates, resulting in a good combination of high strength and toughness. Thus, the strength of $\mathrm{Mn}-\mathrm{Cr}$ steel was improved by nano- $\mathrm{Al}_{2} \mathrm{O}_{3}$. In addition, the investigation shows that the combination of CNTs and oxide nanoparticles enables CNTs to be evenly distributed in the oxide matrix, which is conductive to the tribological properties at high temperature ${ }^{[79]}$. Heat treatment process also plays an important role in the microstructure and properties of steel by influencing the dissolution and precipitation process of the solute. The $\mathrm{Fe}-14 \mathrm{Cr}-$ $2 \mathrm{~W}-0.3 \mathrm{Ti}-0.2 \mathrm{~V}-0.07 \mathrm{Ta}-0.3 \mathrm{Y}_{2} \mathrm{O}_{3}$ alloys with different annealing times were studied. It is found that the microstructure and the whole secondary phase can be controlled by adjusting the annealing process. With the increase of annealing temperature, $\mathrm{M}_{23} \mathrm{C}_{6}$ particles were dissolved and TiC precipitation was promoted. No coarsening of $\mathrm{Y}_{2} \mathrm{Ti}_{2} \mathrm{O}_{7}$ was found ${ }^{[80]}$. $\mathrm{Fe}-14 \mathrm{Cr}$ ODS alloy was prepared by mechanical alloying and spark plasma sintering, and annealed at different temperatures. After annealing at $600{ }^{\circ} \mathrm{C}$ for $5 \mathrm{~h}$, the microstructure stability and strengthening effect were significant ${ }^{[81]}$. After austenitizing at $900{ }^{\circ} \mathrm{C}$ for $20 \mathrm{~min}$, air cooling and tempering at 280 or $370{ }^{\circ} \mathrm{C}$ for $2 \mathrm{~h}$, the full martensite steel is transformed into carbide-free bainite/martensite steel.

\section{Additive manufacturing method}

The conventional preparation process of ceramic nanoparticle reinforced steel includes melting, dispersion and casting, but due to the diversity of physicochemical properties of ceramic particles and steel, it is easy to cause inhomogeneous dispersion and poor interface combination.

In order to overcome these challenges, environmentallyfriendly additive manufacturing (known as 3D printing) has been extensively investigated ${ }^{[82-85]}$. Through computer design and data processing, it is a low-cost, novel and booming technology to obtain complex 3D components directly from the stacked powder layer-by-layer. It is a highly nonequilibrium solidification process. For the metal materials reinforced by ceramic particles fabricated by this method, the content of ceramic particles is usually very high. Selective laser melting is one of the additive manufacturing methods that can realize rapid solidification by high density laser beam and local melting ${ }^{[86,87]}$.

3D printing has become popular all over the world, but it is currently most suitable for plastic and porous steel materials, which are too weak for hard-core applications. Some new technologies have been used to improve additive manufacturing and to obtain more compact, precise and high-quality printed parts, as shown in Fig. 4 (a) ${ }^{[83]}$. At this point in time, researchers have devised a way to 3D print tough and flexible stainless steel, an advance that could lead to faster and cheaper way to make everything from rocket engines to parts for nuclear reactors and oil rigs ${ }^{[88]}$, as shown in Fig. 4 (b). A series of complex cooling, reheating and rolling steps achieves a material with a microscopic structure with tightly packed alloy grains and thin boundaries between the grains that create a cell-like structure. When the metal is bent or stressed, the atom planes in the grains slide past one another, sometimes leading to the interconnection of crystal defects and consequently the fracture. But strong boundaries can prevent these defects, making the material tough but still flexible enough to form the desired shape. The 3D printing researchers from Lawrence Livermore National Laboratory have long been attempting to reproduce this structure. They begin with a layer of powdered metal alloy particles and place them on a flat surface. Then, a computer-controlled high-power laser beam moves back and forth on the surface. The particles are heated by the laser and then melted and fused together. The surface then drops down a step, another layer of powder is added, and the laser heating process is repeated to bind the newly melted material to the layer below. By repeating this tier-by-tier addition, engineers can build complex shapes, such as rocket engines ${ }^{[88]}$.

316L stainless steel reinforced by nano-carbide ceramic particles was successfully fabricated by selective laser melting ${ }^{[89]}$. The acquired microstructure is dense and defect free. The matrix of austenite phase is ultrafine $(0.5 \mu \mathrm{m})$, almost equiaxed, finer than that of unreinforced steel, and the distribution of nano$\mathrm{VC}_{\mathrm{x}}$ reinforcement is uniform. Thus, the mechanical properties
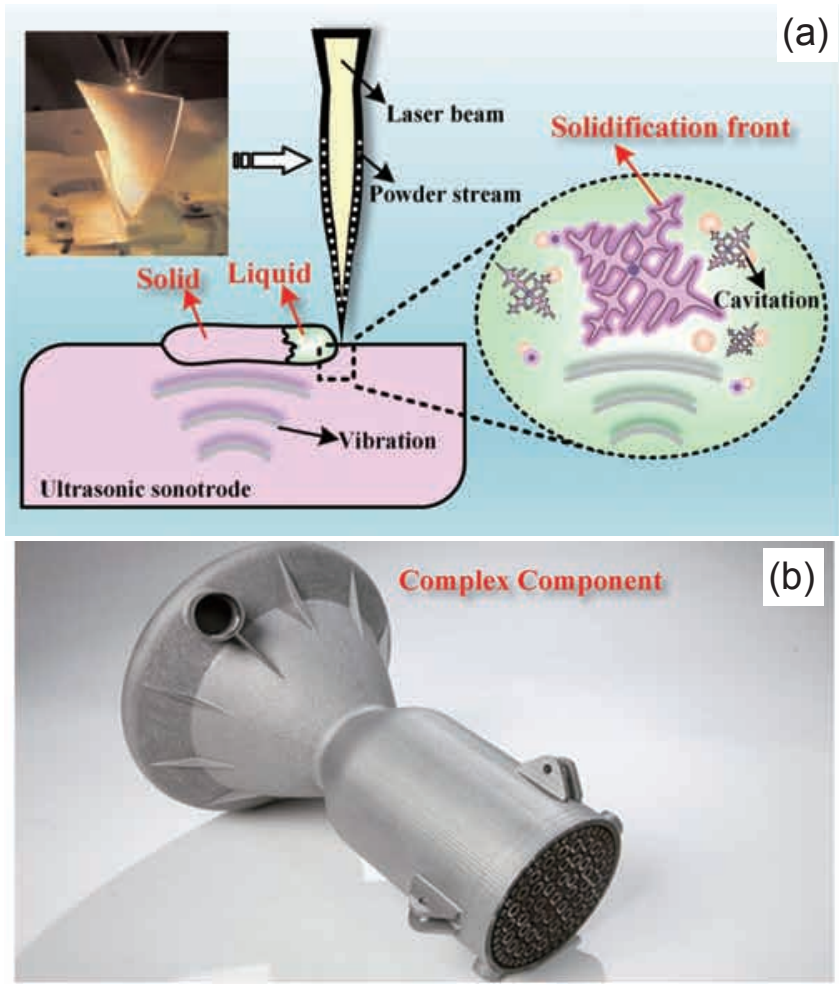

Fig. 4: (a) Improved 3D printing technology, (b) a new technique is set to strengthen the 3D printed stainless steel parts, such as this rocket engine component $^{[86,91]}$

(a)

\section{)}


of the printed $316 \mathrm{~L}$ steel are significantly improved. In the $0.5 \mathrm{wt} . \% \mathrm{TiB}_{2} / \mathrm{S} 136$ mould steel manufactured by selective laser melting, $\mathrm{TiB}_{2}$ particles formed annular nano-sized structures with uniform distribution, with an average thickness of $350 \mathrm{~nm}$, which is conductive to grain refinement and grain-boundary strengthening ${ }^{[90]}$. It is also found that flowability is an important parameter for selective laser melting. As a solid lubricant, nanosized $\mathrm{SiC}$ improves the flowability of $316 \mathrm{~L}$ steel powder. The increase in hardness is due to the dissolution of SiC during heat treatment ${ }^{[91]}$. In addition, the laser energy density used in the selective laser melting process has an effect on the microstructure, hardness and tribological behavior of metal materials. In 316L steel reinforced by $\mathrm{TiC}, \mathrm{TiC}$ is formed by a self-propagating reaction driven by a large negative enthalpy during ball milling, and the $\mathrm{TiC}$ nanoparticles can evenly distribute and refine the microstructure. However, with the decrease of laser energy density, microstructure tends to be finer due to the higher cooling rate. The hardness and wear resistance also change with the variation of laser energy density ${ }^{[92]}$. $\mathrm{Y}_{2} \mathrm{O}_{3}$ strengthened $316 \mathrm{~L}$ steel was prepared by selective laser melting, in which the nano inclusions were finer and distributed uniformly. The effect of $\mathrm{Y}_{2} \mathrm{O}_{3}$ on dislocation pinning and segregation reduces the stress concentration and delays necking, and simultaneously improves the strength and ductility of $316 \mathrm{~L}$ steel ${ }^{[93]}$.

Laser metal deposition is another commonly used additive manufacturing method driven by electron beam or laser, which is used to fabricate near-net shaped structures of various materials. Metallic wire or powder is deposited directly in the molten pool, and different types of powder can be sprayed to the designated location. The improvement of microstructure and performance is realized. Oxide-dispersion strengthened steel was also manufactured by laser metal deposition, and its density was more than $99 \%$. Compared with unreinforced steel, its hightemperature compression strength has also been enhanced ${ }^{[94,95]}$.

\section{Microstructure manipulation and strengthening mechanisms of steel reinforced by nanoparticles}

Nanoparticles play an important role in solid-liquid phase transformation. According to the previous calculation, the heterogeneous nucleation effect depends on the interface energy between the second phase particle substrate and the nucleation phase. The smaller the interface energy is, the more conducive to heterogeneous nucleation. The factors that affect the interface energy are the lattice mismatch $(\delta)$ and electrostatic potential between nucleation substrate and nucleation phase, the chemical properties and surface morphology of nanoparticles, etc. In the solidification process, as shown in Fig. 5, the fine second phase particles dispersed in the molten steel can be used as the heterogeneous nucleation sites of the crystalline primary phase to increase the nucleation rate. Meanwhile, some nanoparticles that are not involved in nucleation will be trapped in the dendrites by the solid-liquid interface, and most of them will be adsorbed at the front of the solid-liquid interface, which will hinder the growth of dendrites, so as to realize the refinement of solidification microstructure ${ }^{[96-98]}$. The grain refinement results in the phenomenon of nucleation sites saturation. In the study of adding $\mathrm{ZrC}$ nanoparticles to the molten liquid of low carbon steel, it is found that when the volume fraction of $\mathrm{ZrC}$ is more than $0.5 \%$, the nucleation sites will tend to be saturated, and the effect of grain refinement is obviously weakened ${ }^{[99]}$. At the same time, the existence of nanoparticles is conducive to inhibit the element segregation, which is beneficial to the refinement and dispersion of precipitates; and the weakening of the ascast microstructure segregation is helpful to the diffusion and uniformity of elements in the process of heat treatment.

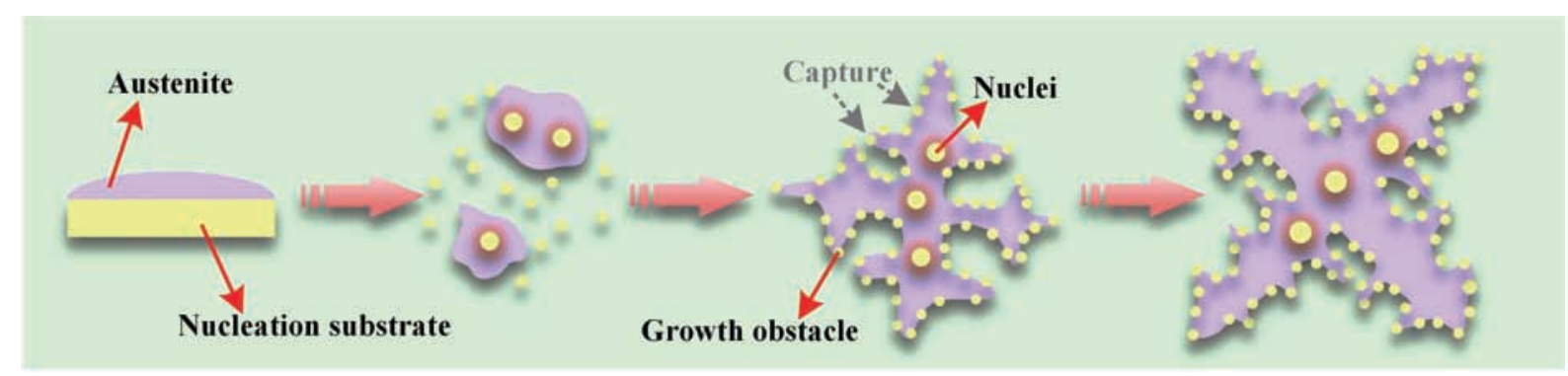

Fig. 5: Schematic illustration of the effects of nanoparticles on the dendritic growth during solid-liquid phase transformation

The nanoparticles in the steel matrix also have a significant effect on the solid-state transformation. In the process of hot working, the fine second phase particles distributed in the steel can hinder the growth of grains. The inhibition depends on the pinning effect of particles on the grain boundary. The smaller the size of nanoparticles and the larger the volume fraction of nanoparticles, the more significant the pinning effect on the grain boundary, and the finer the grains form ${ }^{[100]}$. For example, the lattice mismatch between grains and nanoparticles is very small, so the existence of nanoparticles is equal to the increase of nucleating particles, which can refine grains ${ }^{[101]}$. Due to the fine microstructure obtained and the area of grain boundary increased, the preferred nucleation position increases during the transformation. At the same time, the second phase particles in the grains can also become the nucleation site of grains, which can significantly increase the nucleation rate, refine the grain and promote its more uniformly distribution ${ }^{[102]}$. It has been proved that $\mathrm{Ti}_{2} \mathrm{O}_{3}$ is an effective core for heterogeneous nucleation of intragranular ferrite. Low carbon steel containing $\mathrm{Ti}_{2} \mathrm{O}_{3}$ can form lath-like intragranular ferrite with disordered orientation 
and cross each other, i.e. acicular ferrite ${ }^{[103]}$. Similarly, as shown in Fig. 6, the existence of nanoparticles can promote martensitic transformation, and the distribution of nanoparticles along the martensitic lath can effectively improve the high temperature stability of martensitic structure.

The main strengthening mechanisms of steel reinforced by nanoparticles are grain refinement strengthening, second phase strengthening and comprehensive strengthening of microstructure. Second phase strengthening is the most important strengthening mechanism. Therefore, the reduction degree of ductility caused by the second phase increases with the increase of particle size and volume fraction, but the resulting reduction can be offset by grain refinement ${ }^{[104]}$.

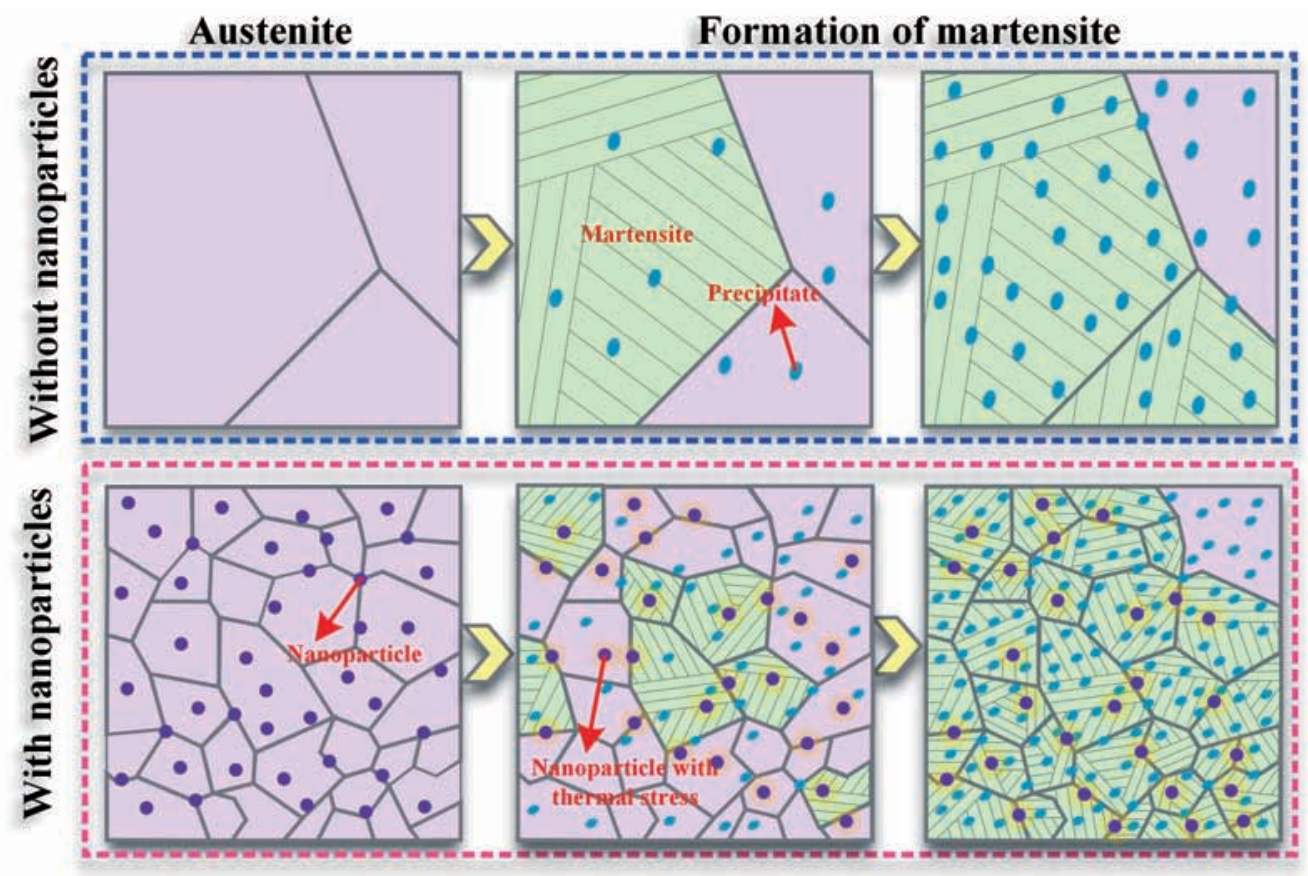

Fig. 6: Schematic illustration showing the effects of nanoparticles on martensitic transformation and precipitated phase during the solid-state phase transformation

\section{Summary}

In recent years, construction for energy, ocean, aviation, equipment, bridges, and other industries has obviously shown a trend toward large-scale and heavy-duty, and the corresponding demand for high-strength and large-scale key basic materials of iron and steel is very urgent. However, with the increase of strength, it is very difficult to improve the comprehensive properties of materials, such as plasticity and toughness, weldability, fatigue resistance, heat resistance/corrosion resistance. The demand for high-quality and high-performance structural materials promotes the innovation demand for efficient strengthening means. The existing ultra-high strength steel is mainly based on the semi coherent intermetallics precipitates and carbides to achieve ultra-high strength. However, the strengthening design of this kind of ultra-high strength steel, which is determined by the interaction of elastic distortion field and dislocation, not only needs to add a lot of expensive alloying elements, but also needs to be melted under harsh conditions. The heat treatment process is complex, the cost is high, and the service safety and reliability also need to be improved. All of these have greatly restricted the application and development of ultra-high strength steel. Therefore, it is an important way to make a breakthrough in the research of new generation of high strength steel by developing innovative strengthening and toughening methods and innovative alloy composition design. At the technical level, it is still an important research direction to explore new methods of nanoparticle high-efficiency strengthening steel. Though there are still some problems with the external particles, but they can stabilize the particle composition and have little influence on the heat treatment process. Meanwhile, in the process of liquid-solid transformation, the external particles can play the role of nucleation and control the growth of dendrites. Therefore, it is still a major research area to develop new methods for efficient addition and dispersion of nanoparticles. At the same time, the action mechanism of the external particles and steel matrix on the nucleation and dendrite growth is also an important part of basic scientific research.

In the aspect of in-situ nanoparticles, the acquisition of nano-sized reinforcement with coherent relationship with steel matrix is especially the main development direction. On the one hand, it can significantly reduce the nucleation barrier of the precipitated phase, promote the uniform distribution of the precipitated phase with high density and good thermal stability, and effectively alleviate the micro elastic distortion around the reinforced particles, consequently improving the macro uniform plastic deformation ability of material. On the other hand, the reinforced phase can effectively prevent dislocation cutting, so as to obtain a new type of aging steel with excellent comprehensive properties. It also opens up a new research 
idea for the development of other ultra-high strength materials. The phase transformation kinetics, strengthening mechanism, size and microstructure characteristics of the nano-sized reinforcements and the compound precipitation in the matrix need further study. Scientific problems such as precipitation behavior and mechanism, the interface structure between precipitation and matrix under plastic deformation, and the temperature field fluctuation of nano-sized reinforcements and compound precipitation all will become research hot topics.

In the field of additive manufacturing (under extreme nonequilibrium solidification), the influence of nanoparticles on the solid-liquid phase transformation and solid-solid phase transformation in steel has been studied. But, the precipitation behavior and mechanism of nano precipitates under the condition of extreme non-equilibrium solidification are still not clear, which will be an important research direction and content in the future. The application properties and strengthening mechanism of nanoparticle reinforced steel, such as plasticity and toughness, creep resistance, heat/corrosion resistance, wear resistance, weldability, fatigue resistance and so on, are also hot topics. In the future, it will be an important research content to control the coarsening of HAZ (heat affected zone), stabilize the microstructure of the weld and HAZ, and improve the welding efficiency of nanoparticle reinforced steel.

Overall, as Professor Greer ${ }^{[105]}$ concluded in a review: "Studies of the effects of nanoparticles added to melts have opened a new field of research." Relevant researchers are invited to keep up with the trends and look forward to the breakthrough of basic research and the implementation of major engineering applications in the field of nano-strengthening metals, so as to benefit our world.

\section{Acknowledgements}

This work was financially supported by the National Natural Science Foundation of China (Grant No. 51971101 and No. 51771081), and the Science and Technology Development Program of Jilin Province, China (No. 20190302004GX).

\section{References}

[1] Bawane K, Lu K. Microstructure evolution of nanostructured ferritic alloy with and without $\mathrm{Cr}_{3} \mathrm{C}_{2}$ coated $\mathrm{SiC}$ at high temperatures. Journal of Materials Science \& Technology, 2020, 43: 126-134.

[2] Jiang $\mathrm{S} \mathrm{H}$, Wang $\mathrm{H}, \mathrm{Wu} \mathrm{Y}$, et al. Ultrastrong steel via minimal lattice misfit and high-density nanoprecipitation. Nature, 2017, 544: 460-464.

[3] Rodríguez E, Pérez A, Mercado-Solis R D, et al. Erosion problem in tool steel using cold box core-making process. China Foundry, 2019, 16(3): 204-210.

[4] Han X, Zhang Z P, Hou J Y, et al. Tribological behavior of shot peened/austempered AISI 5160 steel. Tribology International, 2020, 145: 106197.

[5] Li H C, Liu Y X, Zhang Y H, et al. Effects of hot top pulsed magneto-oscillation on solidification structure of steel ingot. China Foundry, 2018, 15(2): 110-116.

[6] Hao L H, Ji X, Zhang G Q, et al. Carbide precipitation behavior and Mechanical properties of micro-alloyed medium Mn steel. Journal of Materials Science \& Technology, 2020, doi: 10.1016/ j.jmst.2019.12.024.
[7] Zhang C, Zhong H G, Wu C S, et al. Effect of cooling rate and forced convection on as-cast structure of 2205 duplex stainless steel. China Foundry, 2015, 12(1): 32-38.

[8] Dong H. Technological progresses of research activities on steel products. China Metallurgy, 2008, 18(10): 1-1.

[9] Baran E, Alica C. Behavior of cold-formed steel wall panels under monotonic horizontal loading. Journal of Constructional Steel Research, 2012, 79(2): 1-8.

[10] Liu Y C, Liu C X, Sommer F, et al. Martensite formation kinetics of substitutional $\mathrm{Fe}-0.7$ at.\% Al alloy under uniaxial compressive stress. Acta Materialia, 2015, 98: 164-174.

[11] Liu Y C, Wang D J, Sommer F, et al. Isothermal austenite-ferrite transformation of $\mathrm{Fe}-0.04$ at.\% C alloy: dilatometric measurement and kinetic analysis. Acta Materialia, 2008, 56(15): 3833-3842.

[12] Zhang H J, Li C, Guo Q Y, et al. Improving creep resistance of nickel-based superalloy Inconel 718 by tailoring gamma double prime variants. Scripta Materialia, 2019, 164: 66-70.

[13] Zhang K. Design of real time monitor system of manufacture process of iron and steel industry based on new style sensors. Energy Procedia, Part A, 2012, 16 (6): 627-632.

[14] Melchers R E. Long-term corrosion of cast irons and steel in marine and atmospheric environments. Corrosion Science, 2013, 68(9): 186-194

[15] Chen B, Yang J X, Ouyang Z Y. Life cycle assessment of internal recycling options of steel slag in chinese iron and steel industry. Journal of Iron and Steel Research, International, 2011, 18(7): 33-40.

[16] Pan N, Song B, Zhai Q J, et al. Effect of lattice disregistry on the heterogeneous nucleation catalysis of liquid steel. Journal of University of Science and Technology, Beijing, 2010, 32: 179_ 190.

[17] Bramfitt B. The effect of carbide and nitride additions on the heterogeneous nucleation behavior of liquid iron. Metallurgical Transactions, 1970, 1(7): 1987.

[18] Pan N, Song B, Zhai Q J, et al. Lattice disregistry and empirical electron theory study on the heterogeneous nucleation catalysis of liquid steel. Journal of the Chinese Rare Earth Society, 2010, 28: 125-130.

[19] Dong B X, Yang H Y, Qiu F, et al. Design of TiCx nanoparticles and their morphology manipulating mechanisms by stoichiometric ratios: experiment and first-principle calculation. Materials and Design, 2019, 181: 107951.

[20] Dong B X, Qiu F, Li Q, et al. The synthesis, structure, morphology characterizations and evolution mechanisms of nanosized titanium carbides and their other applications. Nanomaterials, 2019, 9: 1152.

[21] Ohashi T, Fujii H, Nuri Y, et al. Effect of oxides on nucleation behavior in supercooled iron. Transactions of the Iron and Steel Institute of Japan, 1977, 17: 262.

[22] Takahashi T, Ohsasa K, Tanaka J. Process for enhancing undercooling of molten steel. Tetsu-to-Hagane, 1988, 74(8): 1601.

[23] Nakajima K, Hasegawa $\mathrm{H}$, Khumkoa S, et al. Effect of a catalyst on heterogeneous nucleation in pure $\mathrm{Fe}$ and $\mathrm{Fe}-\mathrm{Ni}$ alloys. Metallurgical and Materials Transactions B, 2003, 34: 539.

[24] Fischer W, Ackermann W. The oxygen solubility in undercooled iron melts. Arch. Eisenhǜttenwes, 1967, 38(1): 15.

[25] Suzuki T, Inoue J, Koseki T. Solidification of iron and steel on single-crystal oxide. ISIJ International, 2007, 47(6): 847.

[26] Liang G F, Xu Z M, Qu D K, et al. The valence electron criterion on heterogeneous nucleus catalysis during non-equilibrium solidification of austenite steel. Journal of Shanghai Jiaotong University, 2005, 39(7): 1073-1077.

[27] Tiller W, Takahashi T. The electrostatic contribution in heterogeneous nucleation theory: Pure liquids. Acta Metallurgica, 1969, 17(4): 483.

[28] Lei Y, Liu Z Y, Li H. Study on super-fine grains obtained in low carbon section steels by adding ZrC. Iron Steel, 2002, 37(8): 58-60. 
[29] Lei Y, Liu Z Y, Li H. Study on super-fine grain obtained in lowcarbon section steels by adding $\mathrm{ZrO}_{2}$. Ordnance Material Science and Engineering, 2004, 27(2): 3-5.

[30] Wang G C, Wang T M, Li S N. Study on the process of adding $\mathrm{Al}_{2} \mathrm{O}_{3}$ nano-powder to molten pure iron. Journal of University of Science and Technology, Beijing, 2007, 29(6): 579-581.

[31] Wang G C, Fang K M, Wang T M. Study on super-fine particle of TiN added into molten pure iron. Iron Steel Vanadium Titanium, 2006, 27(2): 21-25. (In Chinese)

[32] Li X L, Wang J M, He C L, et al. Effect of nano-SiC particles addition on microstructure and hardness of Q235 Steel. Foundry, 2009, 58(3): 229-231. (In Chinese)

[33] Lazarova R, Petrov R, Gaydarova V, et al. Microstructure and mechanical properties of $\mathrm{P} 265 \mathrm{GH}$ cast steel after modification with TiCN particles. Materials \& Design, 2011, 32(5): 2734-2741.

[34] Wang G C, Huang L, Fang K M. Study on the process of adding $\mathrm{TiO}_{2}$ and $\mathrm{VC}$ superfine particle to molten industrial pure iron. Iron Steel Vanadium Titanium, 2010, 31(1): 17-23. (In Chinese)

[35] Xiao F R, Liao B. Refinement effectiveness of self-prepared (NbTi) C nanoparticles on as-cast 1045 steel. J. Materials and Design, 2018, 139: 531-540.

[36] Li N, Cui C X, Zhao Y Q, et al. Structure and properties of GCr15 modified by multiphase ceramic nanoparticles/Fe-C composite inoculants. Materials Science \& Engineering A, 2018, 738: 6374.

[37] Li C L, Qiu F, Chang F, et al. Simultaneously enhanced strength, toughness and ductility of cast $40 \mathrm{Cr}$ steels strengthened by trace biphase $\mathrm{TiC}_{x}-\mathrm{TiB}_{2}$ nanoparticles. Metals, 2018, 8: 707.

[38] Gao Y Y, Dong B X, Qu F, et al. The superior elevated-temperature mechanical properties of $\mathrm{Al}-\mathrm{Cu}-\mathrm{Mg}-\mathrm{Si}$ composites reinforced with in situ hybrid-sized $\mathrm{TiC}_{x}-\mathrm{TiB}_{2}$ particles. Materials Science and Engineering A, 2018, 728: 157-164.

[39] Huang S G, Li L, Van der Biest O, et al. Influence of WC addition on the microstructure and mechanical properties of $\mathrm{NbC}-\mathrm{Co}$ cermets. Journal of Alloys and Compounds, 2007, 430(12): 158164.

[40] Kitaura $\mathrm{Y}$, Kaneno $\mathrm{Y}$, Takasugi T. Effect of $\mathrm{NbC}$ addition on mechanical properties of dual two-phase $\mathrm{Ni}_{3} \mathrm{Al}-\mathrm{Ni}_{3} \mathrm{~V}$ intermetallic alloy. Materials Science and Engineering: A, 2010, 527(2): 60126019.

[41] Yang K, Liang Y, Yan W, et al. Preferential distribution of boron and its effect on microstructure and mechanical properties of $(9-12) \% \mathrm{Cr}$ martensitic heat resistant steels. Acta Metallurgica Sinica, 2020, 56(1): 53-65.

[42] Wu X, Zuo X R, Zhao W W. Mechanism of TiN fracture during the tensile process of NM500 wear-resistant steel. Acta Metallurgica Sinica, 2020, 56(2): 129-136.

[43] Yu W X, Liu B X, He J N, et al. Microstructure characteristics, strengthening and toughening mechanism of rolled and aged multilayer TWIP/maraging steels. Materials Science and Engineering A, 2019, 767: 138426.

[44] Xu L, Wei D Y, Yu Y, et al. Effect of microstructure on corrosion fatigue behavior of $1500 \mathrm{MPa}$ level carbide-free bainite/martensite dual-phase high strength steel. Journal of Iron and Steel Research, International, 2011, 18(4): 63-67.

[45] Mazaheri Y, Kermanpur A, Najafizadeh A, et al. Effects of initial microstructure and thermomechanical processing parameters on microstructures and mechanical properties of ultrafine grained dual phase steels. Materials Science and Engineering A, 2014, 612: 54-62.

[46] Mao C L, Liu C X, Yu L M, et al. The correlation among microstructural parameter and dynamic strain aging (DSA) in influencing the mechanical properties of a reduced activated ferritic-martensitic (RAFM) steel. Materials Science and Engineering A, 2019, 739: 90-98.

[47] Morris D G, Muñoz-Morris M A. Refinement of second phase dispersions in iron aluminide intermetallics by high-temperature severe plastic deformation. Intermetallics, 2012, 23: 169-176.
[48] Ren X C, Chu W Y, Li J X, et al. The effects of inclusions and second phase particles on hydrogen-induced blistering in iron. Materials Chemistry and Physics, 2008, 107: 231-235.

[49] Xu S S, Zhao Y, Chen D, et al. Nanoscale precipitation and its influence on strengthening mechanisms in an ultra-high strength low-carbon steel. International Journal of Plasticity, 2019, 113: 99-110.

[50] Tian J L, Wang W, Li H B, et al. Effect of deformation on precipitation hardening behavior of a maraging steel in the aging process. Materials Characterization, 2019, 155: 109827.

[51] Kim S H, Kim H, Kim N J. Brittle intermetallic compound makes ultrastrong low-density steel with large ductility. Nature, 2015, 518: 77-79.

[52] Sutou Y, Kamiya N, Umino R, et al. High-strength Fe-20Mn-Al-Cbased alloys with low density. ISIJ International, 2010, 50: 893899.

[53] Frommeyer G, Brüx U. Microstructures and mechanical properties of high-strength Fe-Mn-Al-C light-weight TRIPLEX steels. Steel Research International, 2006, 77: 627-633.

[54] Tähtinen S, Moilanen P, Singh B N, et al. Tensile and fracture toughness properties of unirradiated and neutron irradiated titanium alloys. Journal of Nuclear Materials, 2002, 307-311: 416420.

[55] Marmy P, Leguey T. Impact of irradiation on the tensile and fatigue properties of two titanium alloys. Journal of Nuclear Materials, 2011, 296: 155-164.

[56] Bowen A W. The influence of crystallographic orientation on tensile behaviour in strongly textured Ti6Al4V. Materials Science and Engineering, 1979, 40: 31-47

[57] Dursun T, Soutis C. Recent developments in advanced aircraft aluminium alloys. Materials and Design, 2014, 56: 862-871.

[58] Merati A. In: Corrosion fatigue and environmentally assisted cracking in aging military vehicles (RTO-AG-AVT-140) Ch. 24. Research and Technology Organization, NATO, 2011.

[59] Gil F J, Manero J M, Ginebra M P, et al. The effect of cooling rate on the cyclic deformation of $\beta$-annealed Ti-6Al-4V. Materials Science and Engineering A, 2003, 349: 150-155.

[60] Huang L, Deng X T, Li C R, et al. Effect of TiC particles on threebody abrasive wear behaviour of low alloy abrasion-resistant steel. Wear, 2019, 202971: 434-435.

[61] Celada-Casero C, Huang B M, Yang J R, et al. Microstructural mechanisms controlling the mechanical behaviour of ultrafine grained martensite/austenite microstructures in a metastable stainless steel. Materials and Design, 2019, 181: 107922

[62] Shi R J, Wang Z D, Qiao L J, et al. Microstructure evolution of insitu nanoparticles and its comprehensive effect on high strength steel. Journal of Materials Science and Technology, 2019, 35: 1940-1950.

[63] Gao M Y, Tsai S P, Yang J R, et al. In-situ transmission electron microscopy investigation of compressive deformation in interphase-precipitated carbide-strengthened $\alpha$-iron single-crystal nanopillars. Materials Science and Engineering A, 2019, 746: 406-415.

[64] Chen $Y X$, Hong $Z Y$, Zhang $X X$, et al. Enhanced creep resistance of $Y$-bearing $9 \mathrm{Cr}$ ferritic/martensitic steel via vacuum casting technique. Journal of Materials Research and Technology, 2019, 8(5): 4588-4597.

[65] Yang C Y, Luan Y K, Li D Z, et al. Effects of rare earth elements on inclusions and impact toughness of high-carbon chromium bearing steel. Journal of Materials Science and Technology, 2020, 35(7): 1298-1308.

[66] Qiu G X, Zhan D P, Li C S, et al. Development of nano-structure China low-activation martensitic steel for fusion reactors. Materials Letters, 2019, 252: 248-251.

[67] Zhan D P, Qiu G X, Li C S, et al. Effects of yttrium and zirconium additions on inclusions and mechanical properties of a reduced activation ferritic/martensitic steel. Journal of Iron and Steel Research International, 2020, 27: 197-207. 
[68] Peng H L, Hu L, Zhang X L, et al. Microstructural evolution, behavior of precipitates, and mechanical properties of powder metallurgical high-speed steel S390 during tempering. Metallurgical and Materials Transactions A, 2019, 874: 50A.

[69] Dai L, Liu Z, Yu L M, et al. Microstructural characterization of Mg$\mathrm{Al}-\mathrm{O}$ rich nanophase strengthened $\mathrm{Fe}-\mathrm{Cr}$ alloys. Materials Science and Engineering A, 2020, 777: 138664.

[70] Zhao Q, Yu L M, Liu Y C, et al. Microstructure and tensile properties of a $14 \mathrm{Cr}$ ODS ferritic steel. Materials Science and Engineering A, 2017, 680: 347-350.

[71] Dou P, Qiu L L, Jiang S M, et al. Crystal and metal/oxide interface structures of nanoparticles in $\mathrm{Fe}-16 \mathrm{Cr}-0.1 \mathrm{Ti}-0.35 \mathrm{Y}_{2} \mathrm{O}_{3}$ ODS steel. Journal of Nuclear Materials, 2019, 523: 320-332.

[72] Zhang L Y, Yu L M, Liu Y C, et al. Influence of $\mathrm{Zr}$ addition on the microstructures and mechanical properties of $14 \mathrm{Cr}$ ODS steels. Materials Science and Engineering A, 2017, 695: 66-73.

[73] Peng Y Y, Yu L M, Liu Y C, et al. Microstructures and tensile properties of an austenitic ODS heat resistance steel. Materials Science and Engineering A, 2019, 767: 138419.

[74] Dou P, Sang W, Kimura A. Morphology, crystal and metal/oxide interface structures of nanoparticles in Fe15Cr-2W-0.5Ti-7 Al$0.4 \mathrm{Zr}-0.5 \mathrm{Y}_{2} \mathrm{O}_{3}$ ODS steel. Journal of Nuclear Materials, 2019, 523: 231-247.

[75] Husák R, Hadraba H, Chlup Z, et al. ODS Eurofer steel strengthened by $\mathrm{Y}-(\mathrm{Ce}, \mathrm{Hf}, \mathrm{La}, \mathrm{Sc}$, and $\mathrm{Zr}$ ) complex oxides. Metals, 2019, 9: 1148

[76] Yan F Y, Xiong W, Faierson E, et al. Characterization of nanoscale oxides in austenitic stainless steel processed by powder bed fusion. Scripta Materialia, 2018, 155: 104-108.

[77] Jiménez-Jiménez A, Paniagua-Mercado A M, López-Hirata V M, et al. Improvement of the toughness and ductility of the weld beads by inducing growth of acicular ferrite with $\mathrm{TiO}_{2}$-nanoparticles during submerged arc welding. Materials Research Express, 2019, 6: 106534.

[78] Wang M, Han H N, Chung H S, et al. In situ observation of nanoparticle formation in nickel based mechanical alloyed powders. Journal of Materials Science, 2018, 53: 16110-16121.

[79] Kračun A, Jenko D, Godec M, et al. Nanoparticles reinforcement for the improved strength and high-temperature wear resistance of $\mathrm{Mn}-\mathrm{Cr}$ steel. Metallurgical and Materials Transactions A, 2018, 49A: 5683-5694.

[80] Zhao Q, Ma Z Q, Yu L M. Tailoring the secondary phases and mechanical properties of ODS steel by heat treatment. Journal of Materials Science and Technology, 2019, 35: 1064-1073.

[81] Li Z Y, Chen L J, Zhang H Y, et al. Effect of annealing temperature on microstructure and mechanical properties in oxide dispersion strengthened $\mathrm{Fe}-14 \mathrm{Cr}$ alloys prepared by spark plasma sintering Materials Research Express, 2019, 6: 126515.

[82] Zhang D Y, Qiu D, Gibson M A, et al. Additive manufacturing of ultrafine-grained high-strength titanium alloys. Nature, 2019, 576: 91-95.

[83] Todaro C J, Easton M A, Qu D, et al. Grain structure contro during metal 3D printing by high-intensity ultrasound. Nature Communications, 2020, 11: 142.

[84] Yu C F, Zhang P, Zhang Z F, et al. Microstructure and fatigue behavior of laser-powder bed fusion austenitic stainless steel. Journal of Materials Science and Technology, 2020, 46: 191-200.

[85] Tan C L, Zhou K S, Ma W Y, et al. Research progress of laser additive manufacturing of maraging steels. Acta Metallurgica Sinica, 2020, 56(1): 36-52.

[86] AlMangour B, Kim Y K, Grzesiakc D, et al. Novel TiB2-reinforced $316 \mathrm{~L}$ stainless steel nanocomposites with excellent roomand high-temperature yield strength developed by additive manufacturing. Composites, Part B, 2019, 156: 51-63.

[87] Dadbakhsh S, Mertens R, Hao L, et al. Selective laser melting to manufacture "in situ" metal matrix composites: A review. Advanced Engineering Materials, 2019, 21: 1801244.
[88] Service R F. 3D printing doubles the strength of stainless steel. Science, 2017, doi:10.1126/science.aar3586.

[89] Li B, Qian B, Xu Y, et al. Additive manufacturing of ultrafine-grained austenitic stainless steel matrix composite via vanadium carbide reinforcement addition and selective laser melting: Formation mechanism and strengthening effect. Materials Science and Engineering A, 2019, 745: 495-508.

[90] Wen S F, Hu H, Zhou Y, et al. Enhanced hardness and wear property of $\mathrm{S} 136$ mould steel with nano-TiB2 composites fabricated by selective laser melting method. Applied Surface Science, 2018, 457: $11-20$

[91] Mussatto A, Groarke R, A-Hameed A, et al. Evaluation via powder metallurgy of nano-reinforced iron powders developed for selective laser melting applications. Materials and Design, 2019, 182: 108046.

[92] AIMangour B, Grzesiak D, Yang J M. In situ formation of TiCparticle-reinforced stainless steel matrix nanocomposites during ball milling: feedstock powder preparation for selective laser melting at various energy densities. Powder Technology, 2018 326: 467-478.

[93] Zhong Y, Liu L F, Zou J, et al. Oxide dispersion strengthened stainless steel $316 \mathrm{~L}$ with superior strength and ductility by selective laser melting. Journal of Materials Science and Technology, 2020, 42: $97-105$

[94] Doñate-Buendía C, Frömel F, Wilms M B, et al. Oxide dispersionstrengthened alloys generated by laser metal deposition of lasergenerated nanoparticle-metal powder composites. Materials and Design, 2018, 154: 360-369.

[95] Barkia B, Aubry P, Haghi-Ashtiani P, et al. On the origin of the high tensile strength and ductility of additively manufactured $316 \mathrm{~L}$ stainless steel: multiscale investigation. Journal of Materials Science and Technology, 2020, 41: 209-218.

[96] Baruj A, Kikuchi T, Kajiwara S. TEM observation of the internal structures in $\mathrm{NbC}$ containing Fe-Mn-Si-based shape memory alloys subjected to pre-deformation above room temperature. Materials Science and Engineering: A, 2004, 378(2): 337-342.

[97] Baruj A, Kikuchi T, Kajiwara S, et al. Improvement of shape memory properties of $\mathrm{NbC}$ containing $\mathrm{Fe}-\mathrm{Mn}-\mathrm{Si}$ based shape memory alloys by simple thermomechanical treatments. Materials Science and Engineering: A, 2004, 378(1): 333-336.

[98] Gilliard M B, Pierini B T, Alconchel S A. In situ formation of Fe$\mathrm{NbC/C}$ composite powders from solution-derived precursors by a gas reduction-carburization process. Ceramics International, 2014 40(9): 14881-14889.

[99] Bandyopadhyay T K, Das K. Processing and characterization of ZrC-reinforced steel-based composites. Journal of Materials Processing Technology, 2006, 178(3): 335-341.

[100] Al-Aqeeli N, Abdullahi K, Suryanarayana C, et al. Structure of mechanically milled CNT-reinforced Al-alloy nanocomposites. Materials and Manufacturing Processes, 2013, 28(9): 984-990.

[101] Ashokkumar T, Rajadurai A, Gouthama. Mechanism of reduction in grain and particle sizes of NixFe100-x nanopowder by mechanical alloying. Materials and Manufacturing Processes, 2013, 28(6): 670-675.

[102] Hutchinson C R, Zurob H S, Sinclair C W, et al. The comparative effectiveness of $\mathrm{Nb}$ solute and $\mathrm{NbC}$ precipitates at impeding grainboundary motion in Nb steels. Scripta Materialia, 2008, 59(6) 635-637.

[103] Trung T B, Zuhailawati H, Ahmad Z A, et al. Grain growth, phase evolution and properties of $\mathrm{NbC}$ carbide-doped WC-AISI304 hardmetals produced by pseudo hot isostatic pressing. Journal of Alloys and Compounds, 2013, 552(8): 20-25.

[104] Hossein N S, Farzaneh A. Formation of fine intragranular ferrite in cast plain carbon steel inoculated by titanium oxide nanopowder Scripta Materialia, 2007, 57(10): 937-940.

[105] Greer A L. Overview: Application of heterogeneous nucleation in grain-refining of metals. The Journal of Chemical Physics, 2016 145: 211704. 